medRxiv preprint doi: https://doi.org/10.1101/2021.05.26.21257488; this version posted June 2, 2021. The copyright holder for this preprint (which was not certified by peer review) is the author/funder, who has granted medRxiv a license to display the preprint in perpetuity. It is made available under a CC-BY-NC-ND 4.0 International license .

\title{
Clinical validation of colorimetric RT-LAMP, a fast, highly sensitive and specific COVID- 19 molecular diagnostic tool that is robust to detect SARS-CoV-2 variants of concern
}

Pedro A. Alves ${ }^{1,2^{*}}$, Ellen G. de Oliveira $^{1}$, Ana Paula M. Franco-Luiz ${ }^{1}$, Letícia T. Almeida ${ }^{1}$; Amanda B. Gonçalves ${ }^{1}$, Iara A. Borges ${ }^{1}$, Flávia de S. Rocha ${ }^{1}$; Raissa P. Rocha ${ }^{2}$, Matheus F. Bezerra $^{3}$; Pâmella Miranda ${ }^{4}$; Flávio D. Capanema ${ }^{5}$; Henrique R. Martins ${ }^{6,7}$; Gerald Weber ${ }^{4}$; Santuza M. R. Teixeira², Gabriel Luz Wallau ${ }^{8}$; Rubens L. do Monte-Neto ${ }^{{ }^{*}}$

${ }^{1}$ Instituto René Rachou - Fundação Oswaldo Cruz, Belo Horizonte, 30190-009, Minas Gerais, Brasil;

${ }^{2}$ Centro de Tecnologia em Vacinas, Belo Horizonte, 31310-260, Minas Gerais, Brasil

${ }^{3}$ Depertamento de Microbiologia, Instituto Aggeu Magalhães - Fundação Oswaldo Cruz, Recife, 50670-420, Pernambuco, Brasil

${ }^{4}$ Departamento de Física, Universidade Federal de Minas Gerais, Belo Horizonte, 31270-901, Minas Gerais, Brasil

${ }^{5}$ Núcleo de Inovação Tecnológica - Fundação Hospitalar do Estado de Minas Gerais, Belo Horizonte, 30150-260, Minas Gerais, Brasil

${ }^{6}$ Visuri Equipamentos e Serviços, Belo Horizonte, Minas Gerais, 31330-070, Minas Gerais Brasil

${ }^{7}$ Departamento de Engenharia Elétrica - Universidade Federal de Minas Gerais, Belo Horizonte, 31270-901, Minas Gerais, Brasil

${ }^{8}$ Departamento de Entomologia e Núcleo de Bioinformática, Instituto Aggeu Magalhães Fundação Oswaldo Cruz, Recife, 50670-420, Pernambuco, Brasil

*Corresponding authors: rubens.monte@,fiocruz.br; pedro.alves@fiocruz.br

\section{Abstract}

The COVID-19 pandemics unfolded due to the widespread SARS-CoV-2 transmission reinforced the urgent need for affordable molecular diagnostic alternative methods for massive testing screening. We present the clinical validation of a $\mathrm{pH}$-dependent colorimetric RT-LAMP (reverse transcription loop-mediated isothermal amplification) for SARS-CoV-2 detection. The method revealed a limit of detection of $19.3 \pm 2.7$ viral genomic copies/ $\mu \mathrm{L}$ when using RNA extracted samples obtained from nasopharyngeal swabs collected in guanidine-containing viral transport medium. Typical RT-LAMP reactions were performed at $65{ }^{\circ} \mathrm{C}$ for $30 \mathrm{~min}$. When compared to RT-qPCR, up to Ct value 32, RT-LAMP presented 97\% (87.4-99.4\% 95\% CI) sensitivity and 100\% (86.2-100\%) specificity for SARS-CoV-2 RNA detection targeting N gene. No cross-reactivity was detected when testing other non-SARS-CoV virus, confirming high specificity. The test is compatible with primary RNA extraction free samples. We also

NOTE: This preprint reports new research that has not been certified by peer review and should not be used to guide clinical practice. 1 
medRxiv preprint doi: https://doi.org/10.1101/2021.05.26.21257488; this version posted June 2, 2021. The copyright holder for this preprint (which was not certified by peer review) is the author/funder, who has granted medRxiv a license to display the preprint in perpetuity. It is made available under a CC-BY-NC-ND 4.0 International license.

demonstrated that colorimetric RT-LAMP can detect SARS-CoV-2 variants of concern (VOC) and variants of interest (VOI), such as variants occurring in Brazil named P.1, P.2, B.1.1.374 and B.1.1.371. The method meets point-of-care requirements and can be deployed in the field for highthroughput COVID-19 testing campaigns, especially in countries where COVID-19 testing efforts are far from ideal to tackle the pandemics. Although RT-qPCR is considered the gold standard for SARS-CoV-2 RNA detection, it requires expensive equipments, infrastructure and highly trained personnel. In contrast, RT-LAMP emerges as an affordable, inexpensive and simple alternative for SARS-CoV-2 molecular detection that can be applied to massive COVID-19 testing campaigns and save lives.

Keywords: COVID-19; RT-LAMP; SARS-CoV-2; molecular test; colorimetric; respiratory virus 
medRxiv preprint doi: https://doi.org/10.1101/2021.05.26.21257488; this version posted June 2, 2021. The copyright holder for this preprint (which was not certified by peer review) is the author/funder, who has granted medRxiv a license to display the preprint in perpetuity. It is made available under a CC-BY-NC-ND 4.0 International license .

\section{INTRODUCTION}

Emerging viral infections continue to pose a major threat to global public health. In the past decades different viral emergencies have been reported including the severe acute respiratory syndrome coronavirus (SARS-CoV), H1N1 influenza, Middle East respiratory syndrome coronavirus (MERS-CoV), Ebola vírus, Zika virus and most recently the new coronavirus has been described, which cause COVID-19 $(1,2)$. COVID-19 has as etiologic agent the severe acute respiratory syndrome coronavirus 2 (SARS-CoV-2), which belongs to the Coronaviridae family, Betacoronavirus genus $(3,4)$. People with COVID-19 have a wide range of symptoms reported such as fever, cough, anosmia, ageusia, headache, fatigue, muscle or body aches, sore throat, shortness of breath or difficulty breathing. Some of these symptoms help spread the virus, however human-to-human transmission from infected individuals with no or mild symptoms has been extensively reported (5,6). This outbreak has spread rapidly, as of May 2021, there were over 165 million confirmed COVID-19 cases with over 3,4 million deaths recorded worldwide (https://coronavirus.jhu.edu/). Isolation and quarantine of infected individuals is essential to viral spread and community dissemination of airborne pathogens and requiring an accurate, fast, affordable, readily available tests for massive population testing. In contrast do antibody detection, which may take weeks after the onset of the infection. Detection of viral RNA is the best way to confirm the acute infection phase, the most important phase for viral shedding, so that rationally managed social distancing and lockdown can be implemented $(1,7)$.

Quantitative reverse transcription-polymerase chain reaction (RT-qPCR) is considered the gold standard method for SARS-CoV-2 RNA detection, mainly targeting combinations of viral genome regions that codes for nucleocapsid protein $(N)$, envelope protein $(E)$, RNA-dependent RNA polymerase (RdRp) and other targets on the open reading frame (ORF1ab) (8). Although RT-qPCR assays have played an important role un the SARS-CoV-2 diagnosis; the technique has limitations for massive population testing such as processing time, the requirement of sophisticated equipment, infrastructure and highly trained personnel, as well as costly reagents with high demand and shortages around the world. Thus, developing complementary, inexpensive point-ofcare $(\mathrm{PoC})$ methods that are rapid, simple, allowing the use of alternative reagents for COVID-19 diagnosis test, is urgently needed. Methods gathering these features can make affordable massive testing campaigns, including contact tracing strategies in highly dense countries, saving lives (917). In this regard reverse transcription loop-mediated isothermal amplification (RT-LAMP) has 
medRxiv preprint doi: https://doi.org/10.1101/2021.05.26.21257488; this version posted June 2, 2021. The copyright holder for this preprint (which was not certified by peer review) is the author/funder, who has granted medRxiv a license to display the preprint in perpetuity. It is made available under a CC-BY-NC-ND 4.0 International license .

been shown to be an affordable technique applied to detect different pathogens $(18,19)$. RT-LAMP has been used during Ebola outbreak (20,21) and for tracking Zika virus (22) or Wolbachia (23) in Brazilian mosquitoes. The method relies on specific DNA amplification at constant temperature without the need for sophisticated thermal cyclers (24). The amplified products can be visually detected by magnesium pyrophosphate precipitation; fluorescence emission by DNA intercalating dyes; agarose gel electrophoresis; lateral flow immunochromatography; magnesium chelating color indicators and $\mathrm{pH}$-dependent colorimetric reaction that changes from fuchsia (pink) to yellow (positive result) due to proton release during nucleic acid amplification (25) (Figure 1). The possibility of accessing results by naked eye, made RT-LAMP an exciting alternative that facilitates the use of COVID-19 molecular testing. Simple, scalable, cost-effective RT-LAMPbased alternatives for SARS-CoV-2 detection, has emerged during pandemics including protocols for viral inactivation, quick run, RNA extraction-free and LAMP-associated CRISPR/Cas strategies $(10,11,14,16,17,26-32)$. On April 14 ${ }^{\text {th }}, 2020$, the RT-LAMP received the emergency use authorization from the United States Food and Drug Administration for SARS-CoV-2 detection in COVID-19 diagnostics.

In this study, we validate a colorimetric RT-LAMP assay to detect SARS-CoV-2 RNA in clinical samples collected in different parts of Brazil, including samples with known SARS-CoV2 variants of interest and concern. After testing primers used by RT-LAMP SARS-CoV-2 RNA detection targeting different regions, best results were achieved when using $N$ gene or $N / E$ genesbased strategies. One hundred nasopharyngeal swabs collected in a guanidine-containing viral transport medium (VTM) (33) from symptomatic hospitalized patients were tested. The clinical validation revealed a sensitivity of 97\% (87.4-99.4 95\% CI) with samples ranging $\mathrm{Ct}$ values from 15 to 32 with $100 \%$ specificity. The use of RNA extraction-free samples was also tested, although there is a loss in sensitivity. We also demonstrated that RT-LAMP is affordable for the detection of more transmissible SARS-CoV-2 variants encompassing a number of genomic nucleotide changes. Part of the results presented here are the research basis of OmniLAMP ${ }^{\circledR}$ SARS-CoV-2 kit which was approved by the Brazilian Heath Regulatory Agency for COVID-19 molecular testing (Anvisa $\mathrm{n}^{\mathrm{o}}$ : 10009010368) as an alternative for massive decentralized diagnostic in Brazil, that records the third-highest COVID-19 cases number worldwide (https://coronavirus.jhu.edu). Together with vaccination, RT-LAMP for COVID-19 diagnosis could help to improve better life quality during pandemics, offering an alternative molecular testing for monitoring lock-down 
medRxiv preprint doi: https://doi.org/10.1101/2021.05.26.21257488; this version posted June 2, 2021. The copyright holder for this preprint (which was not certified by peer review) is the author/funder, who has granted medRxiv a license to display the preprint in perpetuity.

It is made available under a CC-BY-NC-ND 4.0 International license .

measures; traveling restrictions; the return of universities, schools, kindergartens; sport leagues (including the presence of audience, in the Olympics for example) activities with worldwide impact.

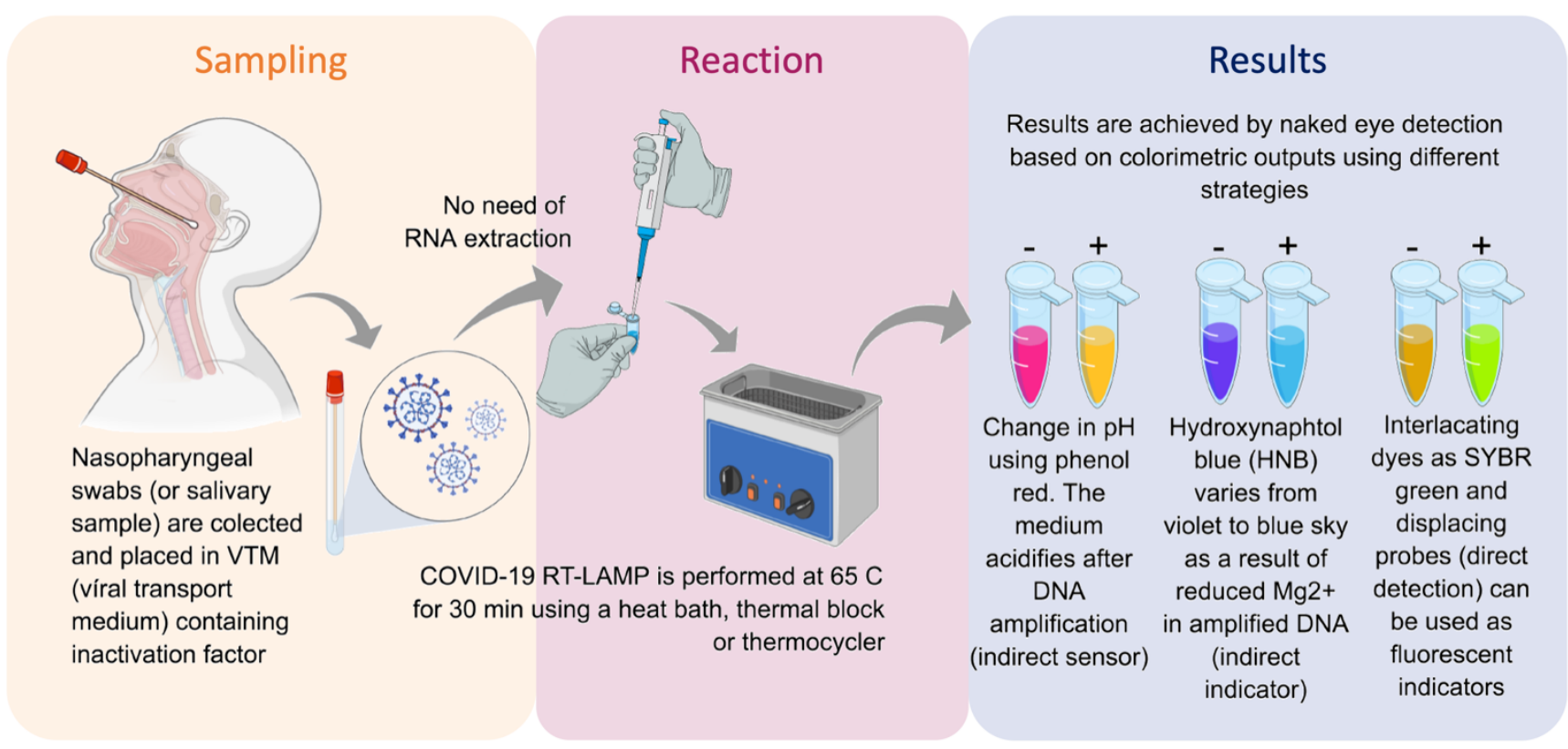

Figure 1 - Reverse transcription loop-mediated isothermal amplification (RT-LAMP) for SARS-CoV-2 RNA

detection and COVID-19 testing. Inactivated saliva samples or from nasopharyngeal swabs can processed for RNA extraction previously or be directly added to RT-LAMP reaction. Colorimetric output can be achieved by different sensors and can be read by naked eye. The whole procedure is rapid, simple and do not requires complex infrastructures. 
medRxiv preprint doi: https://doi.org/10.1101/2021.05.26.21257488; this version posted June 2, 2021. The copyright holder for this preprint (which was not certified by peer review) is the author/funder, who has granted medRxiv a license to display the preprint in perpetuity. It is made available under a CC-BY-NC-ND 4.0 International license .

\section{RESULTS}

\section{RT-LAMP targeting SARS-CoV-2 $N$ and E genes can detect as low as 19 viral copies/ $\mu L$}

In order to access absolute analytical sensitivity of the colorimetric RT-LAMP for SARSCoV-2 detection, we calculated the limit of detection (LoD), which is the lowest detectable

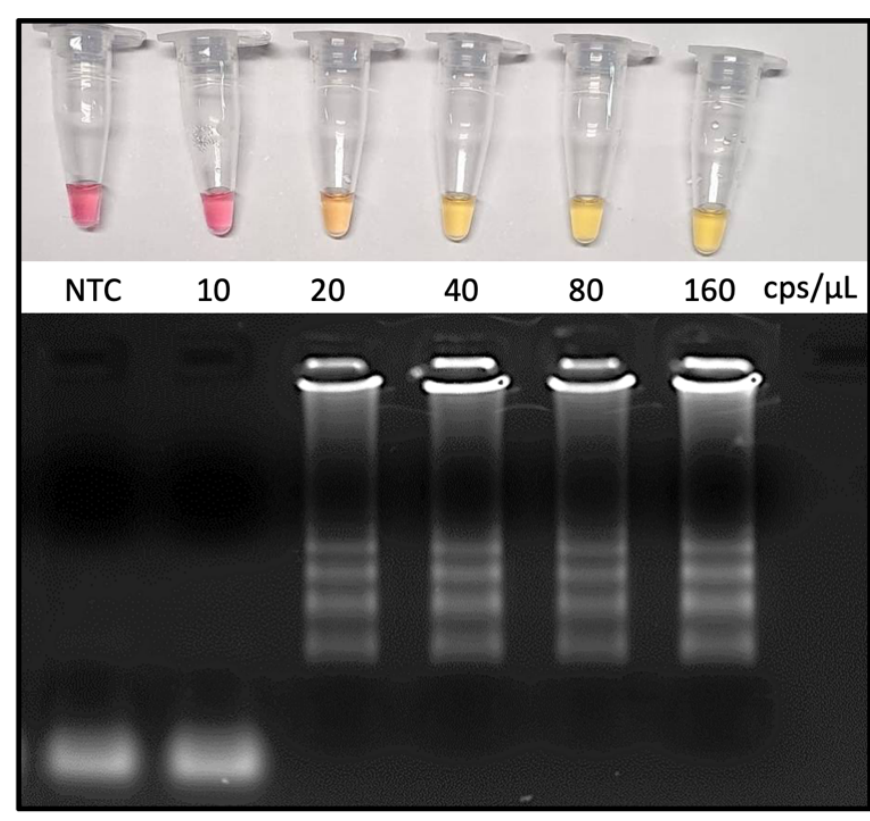

Figure 2 - Analytical sensitivity as revealed by the limit of detection (LoD). RNA was extracted from VTMnasopharyngeal swab and the genome viral copies input was calculated based on SARS-CoV-2 E gene-harboring plasmid (Bioclin \#K228-1) calibration curve. RT-LAMP reaction was performed at $65{ }^{\circ} \mathrm{C}$ during 30 min using WarmStart ${ }^{\circledR}$ colorimetric master LAMP mix (NEB \#M1800) in $20 \mu \mathrm{L}$ final volume (upper panel). Amplicons were resolved in $2 \%$ agarose gel and stained with GelRed ${ }^{\circledR}$ (Biotium \#41003) to confirm DNA amplification (bottom panel). cps $/ \mu \mathrm{L}$ : viral genome copies per microliter; NTC: non-template control; VTM: viral transport medium (Bioclin \#G092-1). concentration of viral nucleic acid - here represented in viral copies per microliter (cps $/ \mu \mathrm{L}$ ), which was determined based on a calibration curve from a known copy number load standard $\mathrm{E}$ gene-harboring plasmid. Purified SARS-CoV-2, obtained from infected Vero E6 cells revealed a LoD equivalent to $0.44 \pm 0.2 \mathrm{cps} / \mu \mathrm{L}$ while RNA obtained from clinical samples (nasopharyngeal swab in viral transport medium - VTM) resulted in a LoD of $19.3 \pm$ $2.7 \mathrm{cps} / \mu \mathrm{L}$. Validation was performed using clinical samples, confirming the LoD by colorimetric RT-LAMP as well as by the visualization of the amplified DNA in agarose gel (Figure 2).

\section{SARS-CoV-2 detection by RT-LAMP on clinical samples having $N$ gene as target present 100\% specificity while sensitivity varies from 100-87\% depending on the viral load}

The diagnostic accuracy for RT-LAMP was compared to the "gold standard" technique RT-qPCR. The relative sensitivity was accessed in a panel of 100 clinical specimens from nasopharyngeal swab collected in VTM, including 60 positive and 40 negative samples according to the colorimetric RT-LAMP output (Figure 3) that were previously characterized by RT-qPCR 
medRxiv preprint doi: https://doi.org/10.1101/2021.05.26.21257488; this version posted June 2, 2021. The copyright holder for this preprint (which was not certified by peer review) is the author/funder, who has granted medRxiv a license to display the preprint in perpetuity. It is made available under a CC-BY-NC-ND 4.0 International license.

(Table 1). The colorimetric output was correlated with the visualization of amplified DNA after agarose gel electrophoresis.
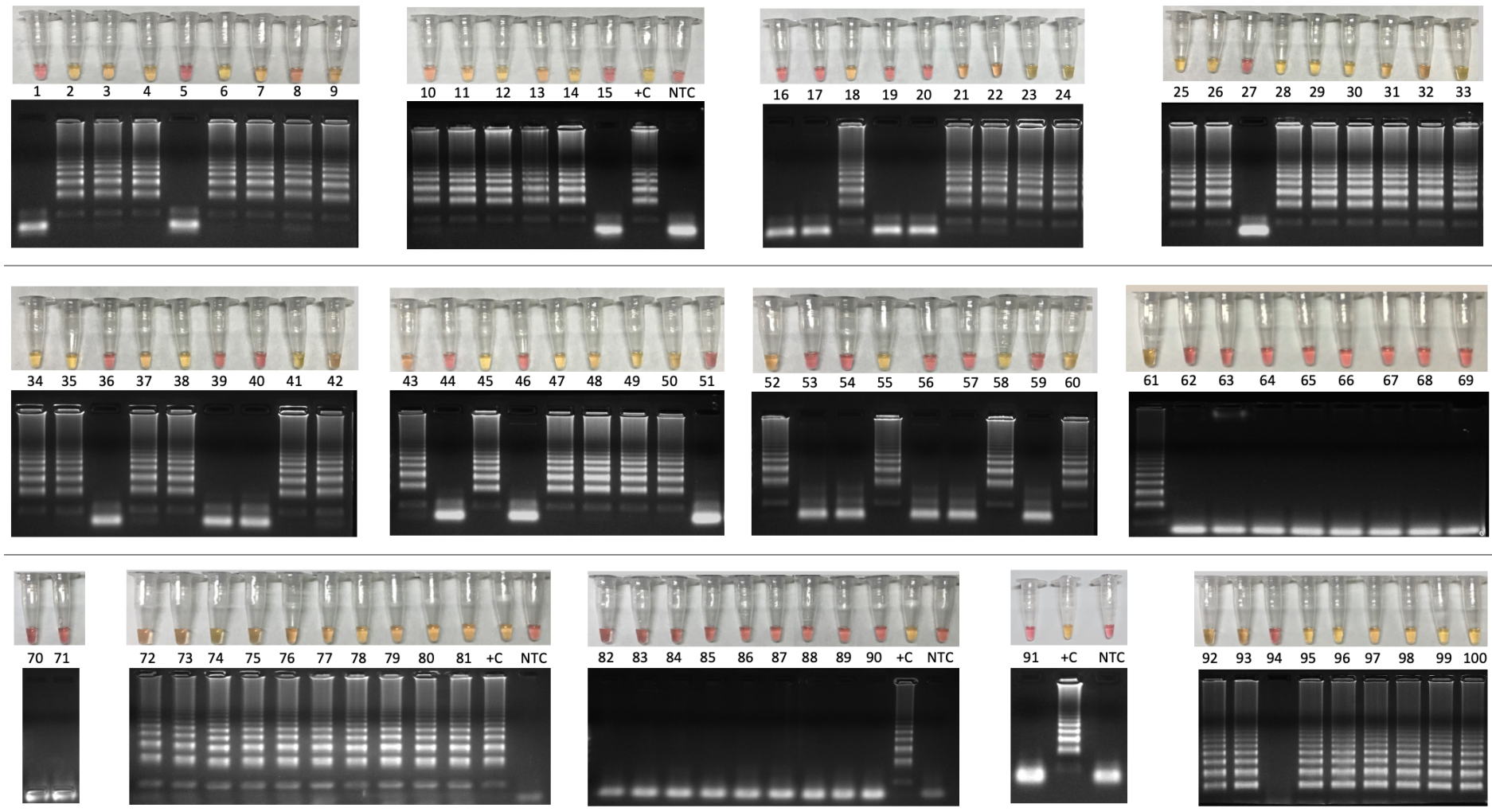

Figure 3 - Colorimetric RT-LAMP for COVID-19 diagnosis validation using one hundred clinical samples. Clinical samples were collected from symptomatic patients by nasopharyngeal swabs in partnership with CT-Vacinas/UFMG, Belo Horizonte, Brazil. Samples were obtained from different parts including Brazilian Southeast and Northeast regions. The reaction was performed at 65 ${ }^{\circ} \mathrm{C}$ during 30 min using WarmStart ${ }^{\circledR}$ colorimetric LAMP master mix (NEB \#M1800) in $20 \mu \mathrm{L}$ final volume. The RT-LAMP reaction targeted SARS-CoV-2 N gene. Yellow content indicate positive reaction while pink pattern reveal non-reagent samples. Amplicons were resolved in $2 \%$ agarose gel and stained with GelRed $^{\circledR}$ (Biotium \#41003) to confirm DNA amplification. Latter pattern confirmed specific SARS-CoV-2 amplification that matches with yellow output tubes which is not observed in pink non-reagent tests. $+\mathrm{C}$ : positive control using RNA extracted from laboratory-Vero E6 cultured inactivated SARS-CoV-2. NTC: non-template control.

The overall accuracy of colorimetric RT-LAMP compared to RT-qPCR was 91\%, considering RT-qPCR Ct values ranging from 15 to 36, with relative sensitivity of $87 \%$ (95\% CI 76.1-93.5\%) and 100\% (95\% CI 86.2-100\%) specificity (Table 1). However, considering samples with equivalent RT-qPCR Ct value $\leq 32$, RT-LAMP sensitivity is 97\% (95\% CI 87.4-99.4\%) and reaches $100 \%$ (95\% CI 90-100\%) in samples with Ct value $\leq 30$, while specificity is always $100 \%$ (Table 1), which means there are no false positive hits. It is noteworthy that some samples with RT-qPCR Ct $>32$ had false negatives results for RT-LAMP (Table 1 and Figure 4A). However, other four samples were detected as positive on RT-LAMP with RT-qPCR Ct values ranging from 32-36 (Figure 4A). Analysis by receiver operating characteristic (ROC) curve confirmed high 
medRxiv preprint doi: https://doi.org/10.1101/2021.05.26.21257488; this version posted June 2, 2021. The copyright holder for this preprint (which was not certified by peer review) is the author/funder, who has granted medRxiv a license to display the preprint in perpetuity. It is made available under a CC-BY-NC-ND 4.0 International license .

sensitivity and specificity at RT-PCR equivalent Ct value 31.8 for RT-LAMP on COVID-19 diagnostics (Figure 4B)

Table 1 - Comparison of clinimetric parameters between colorimetric RT-LAMP and RT-qPCR on the detection of SARS-CoV-2 for molecular diagnosis of COVID-19

\begin{tabular}{|c|c|c|c|c|c|c|c|}
\hline \multirow{2}{*}{$\begin{array}{c}\text { RT-qPCR } \\
\text { Ct value }\end{array}$} & \multicolumn{2}{|c|}{ Colorimetric RT-LAMP } & \multicolumn{5}{|c|}{ Metrics \% $(95 \% \mathrm{Cl})$} \\
\hline & Positive & Negative & Sensitivity & Specificity & Accuracy & PPV & NPV \\
\hline $15-30$ & 44 & 0 & $100(89.9-100)$ & $100(86.2-100)$ & 100 & $100(89.9-100)$ & $100(86.2-100)$ \\
\hline $15-32$ & 58 & 2 & $97(87.4-99.4)$ & $100(86.2-100)$ & 97.8 & $100(92.2-100)$ & 93.9 (78.3-98.9) \\
\hline $15-34$ & 58 & 8 & $88(76.9-94.2)$ & $100(86.2-100)$ & 90.8 & $100(92.2-100)$ & $79.4(63-90.1)$ \\
\hline $15-36$ & 60 & 9 & $87(76.1-93.5)$ & $100(86.2-100)$ & 91 & $100(92.5-100)$ & $77.5(61.1-88.6)$ \\
\hline Negative & 0 & 31 & & & & & \\
\hline
\end{tabular}

Considering the overall range of RT-qPCR Ct values from 15-36, and as an example, we can define the relative sensitivity as $[(60 / 69) * 100]$; relative specificity as $[(31 / 31) * 100]$ and accuracy as $[(60+31) /(60+0+9+31) * 100]$. PPV: positive predicted value, or probability for true positive, defined as the probability of a true teste positive subject have the disease. The opposite is defined for the NPV: negative predicted value.

A

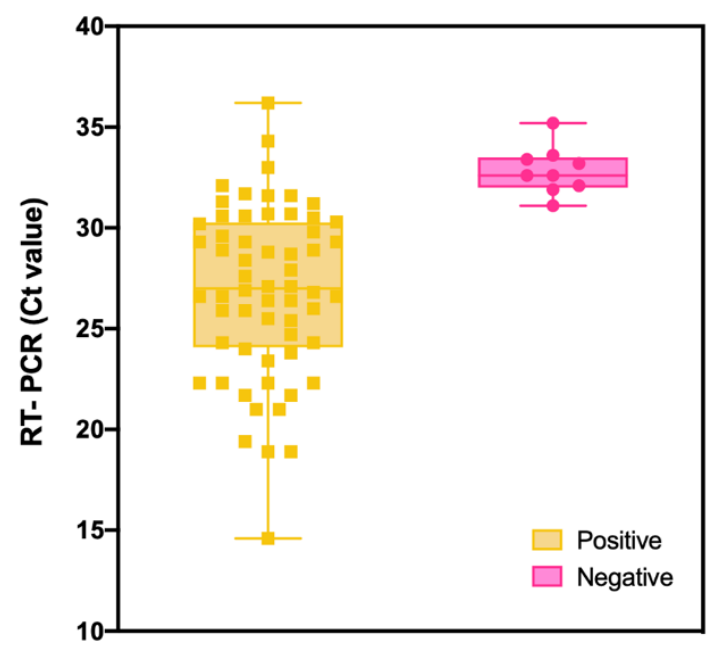

RT-LAMP SARS-CoV-2

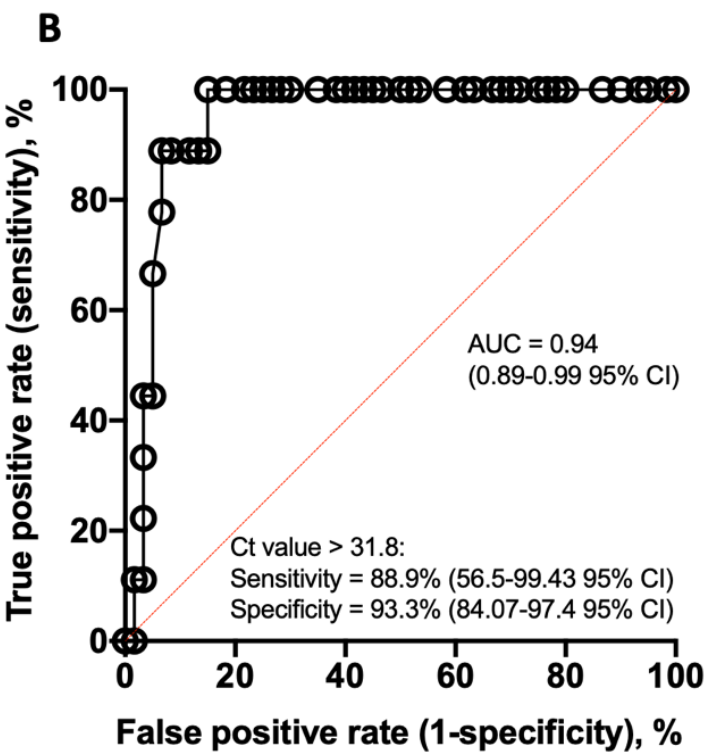

Figure 4 - Colorimetric RT-LAMP for SARS-CoV-2 RNA detection. A) Box and whisker representation of colorimetric RT-LAMP SARS-CoV-2 positive and negative output (x axis) plotted in function of their respective RT-PCR Ct values (y axis). Nine false negative samples were detected on RTLAMP after $\mathrm{Ct} 32$ despite other four being positive from Cts ranging from 32-36. B) Receiver operating characteristic (ROC) curve constructed based on data presented in A. As summarized in Table 1, high sensitivity and specificity values were obtained at the predicted cut-off.

\section{RT-LAMP targeting SARS-CoV-2 N gene do not cross-reacted with other viruses, including respiratory ones}

The analytical specificity was confirmed by performing RT-LAMP for SARS-CoV-2 on putative cross-reacting viruses such as pathogens that colonizes the human upper respiratory tract 
medRxiv preprint doi: https://doi.org/10.1101/2021.05.26.21257488; this version posted June 2, 2021. The copyright holder for this preprint (which was not certified by peer review) is the author/funder, who has granted medRxiv a license to display the preprint in perpetuity. It is made available under a CC-BY-NC-ND 4.0 International license .

or that are associated with seasonal outbreaks in Brazil. None of the tested viruses (human Influenza A virus/H1N1; Influenza B virus; human respiratory syncytial virus, Dengue, Zika and Chikungunya viruses) presented cross-reactivity on RT-LAMP using N gene as SARS-CoV-2 target (Figure 5). It reinforces the high specificity observed on clinical validation with no false positive results (Figure 3). Thermodynamic and alignment analyses were performed on SARSCoV-2 N, E and RdRp RT-LAMP primer sets, revealing that there is no cross-reactivity over more than 300 non-SARS coronaviruses-derived genomes (Table S1).
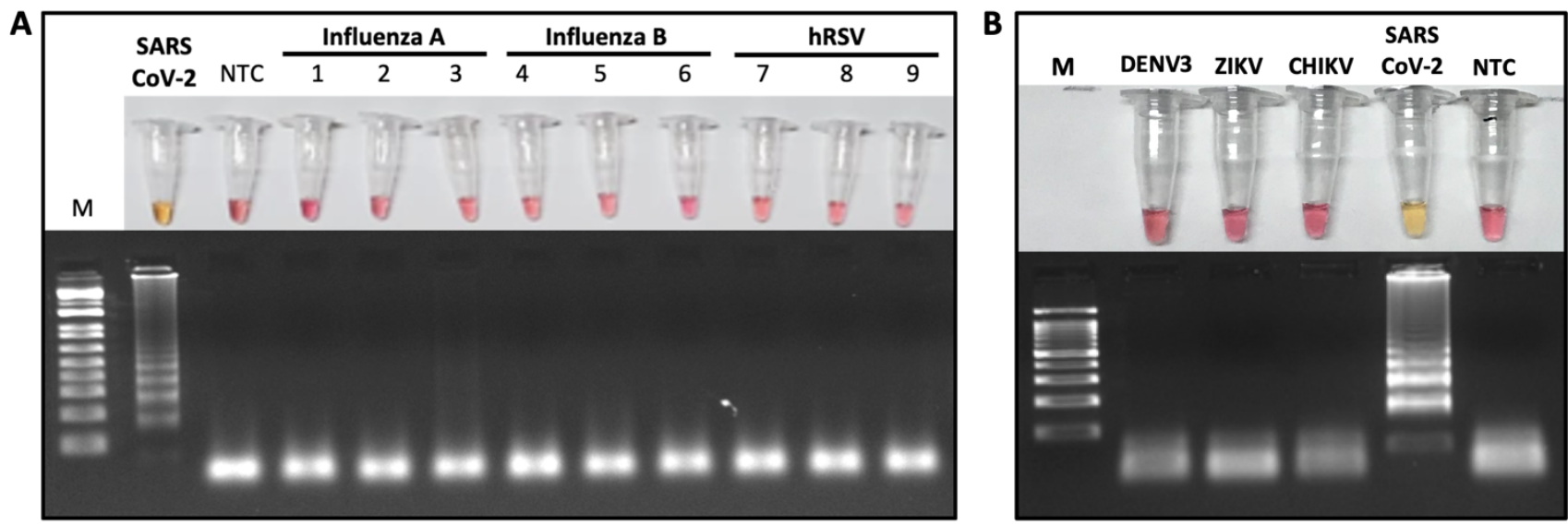

Figure 5 - Microbial cross-reactivity assay to test SARS-CoV-2 RT-LAMP analytical sensitivity. The test was performed using potentially cross-reacting respiratory viruses (A) or local occurring arboviruses (B). RT-LAMP reaction was performed at $65^{\circ} \mathrm{C}$ during $30 \mathrm{~min}$, with additional $10 \mathrm{~min}$, to confirm the absence of cross-reactivity when using SARS-CoV-2 $\mathrm{N}$ gene as target. The assay was performed using the WarmStart ${ }^{\circledR}$ colorimetric LAMP $2 \mathrm{x}$ master mix (NEB \#M1800). Yellow (positive) reaction is only observed when the template is SARS-CoV-2 viral RNA. hRSV: human respiratory syncytial virus; NTC: non-template control; M: molecular size marker. RT-LAMP amplification products were resolved in 2\% agarose gel and stained with GelRed ${ }^{\circledR}$ (Biotium \#41003) to confirm DNA amplification. DENV3: Dengue virus serotype 3; ZIKV: Zika virus; CHIKV: Chikungunya virus; Influenza A (H1N1/H3N2); Influenza B (Yamagata/Victoria).

\section{SARS-CoV-2 $N$ gene favors sensitivity when compared to $E$ and $R d R p$ genes as target for singleplex RT-LAMP}

Six clinical samples previously confirmed as SARS-CoV-2 positive by RT-qPCR were subclassified as presenting low, medium or high $\mathrm{Ct}$ values for E gene as target. All of them were tested by colorimetric RT-LAMP in independent reactions to test the performance of N, E and RdRp genes as target to detect SARS-CoV-2. The low Ct values (18.9 and 21.7) samples were positive for all tested primer sets, while $\mathrm{E}$ and RdRp genes started to present false negative results from medium (26.6 and 28.4) $\mathrm{Ct}$ values (Figure 6). It indicates that the SARS-CoV-2 $\mathrm{N}$ gene is a 
medRxiv preprint doi: https://doi.org/10.1101/2021.05.26.21257488; this version posted June 2, 2021. The copyright holder for this preprint (which was not certified by peer review) is the author/funder, who has granted medRxiv a license to display the preprint in perpetuity.

It is made available under a CC-BY-NC-ND 4.0 International license .

better target for colorimetric RT-LAMP, detecting viral RNA in samples with equivalent RTqPCR Ct values over 30 (Figure 6).
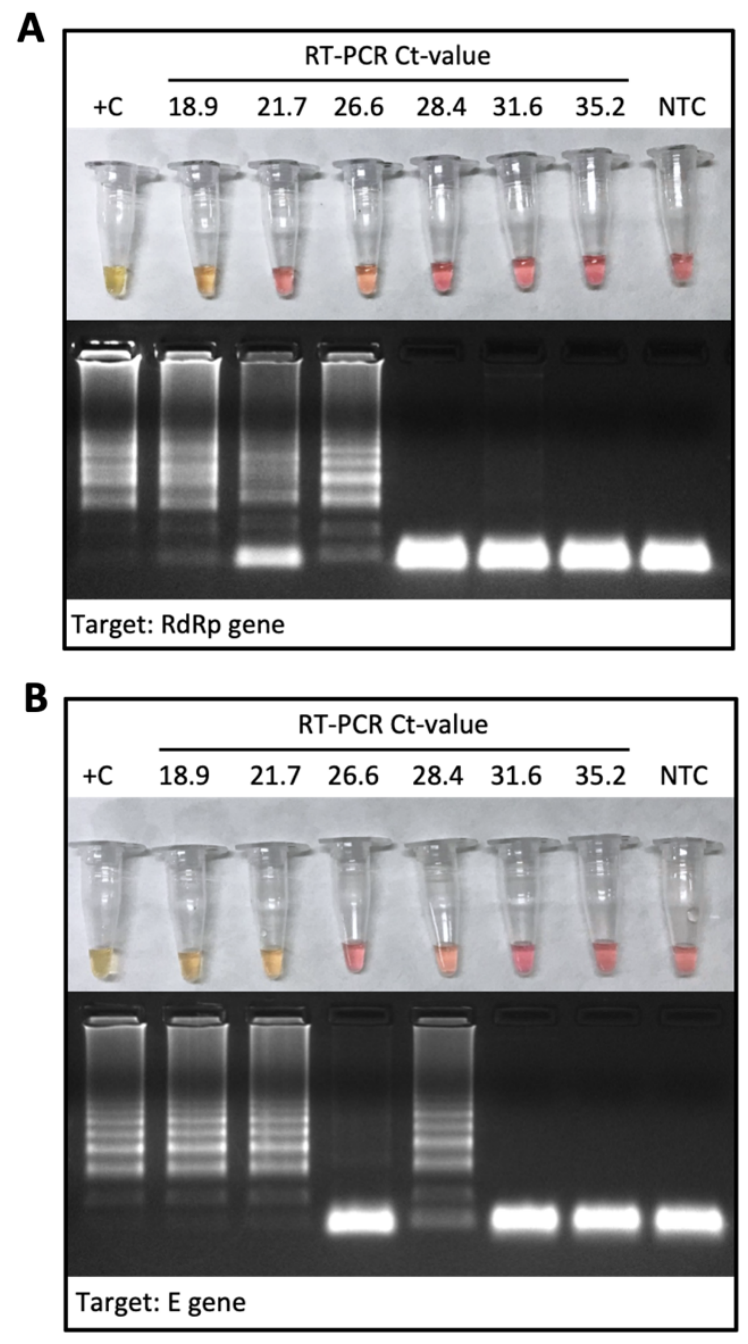

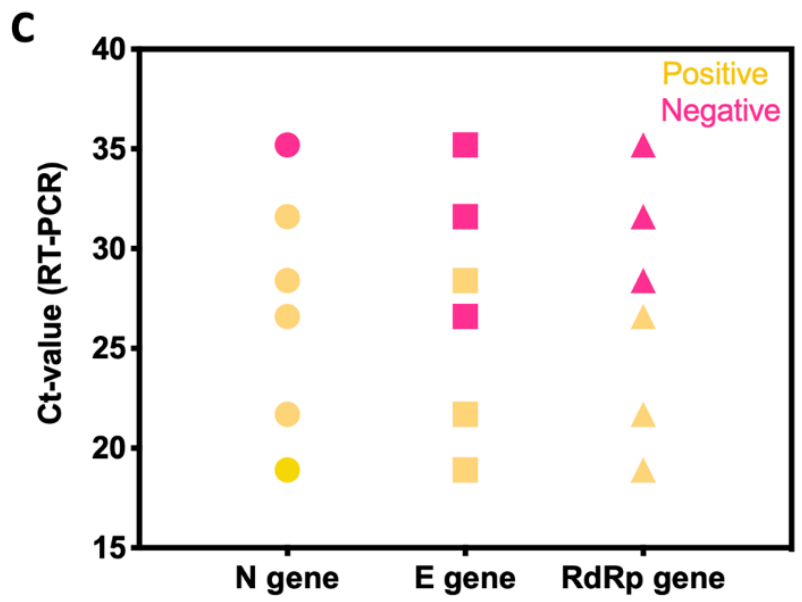

Figure 6 - Colorimetric RT-LAMP for SARS-CoV2 detection using genes $\mathrm{N}, \mathrm{E}$ and RdRp as target. Selected SARS-CoV-2 positive clinical samples by RTqPCR were classified as low ( $\mathrm{Ct} 18.9$ and 21.7); medium (Ct 26.6 and 28.4) and high (Ct 31.6 and 35.2) $\mathrm{Ct}$ values for $\mathrm{E}$ gene. They were included as input for colorimetric RT-LAMP reaction using primers targeting N, RdRp (A) and E genes (B). RT-LAMP SARS-CoV-2 false negative samples are more frequent when using E and RdRp genes as target (C). RT-LAMP reaction was performed at $65^{\circ} \mathrm{C}$ during $30 \mathrm{~min}$, using the WarmStart ${ }^{\circledR}$ colorimetric LAMP 2x master mix (NEB \#M1800). RT-LAMP amplification products were resolved in $2 \%$ agarose gel and stained with GelRed $^{\circledR} \quad$ (Biotium \#41003) to confirm DNA amplification. $+\mathrm{C}$ : positive control using SARS-CoV-2 RNA extracted from laboratory-cultured inactivated SARS-CoV-2. NTC: non-template control.

Colorimetric RT-LAMP sensitivity depends on the set of LAMP primers that can vary even within the same target. When RT-LAMP was performed on low viral load samples (Ct value for E gene ranging from 31.8 - 36.2), the N gene_Set1 was able to identify 4 out of $12(33.3 \%)$ true positive samples. In contrast, $\mathrm{N}$ gene_Set2 or primer multiplex strategy (N gene Set1/Set2) allowed the detection of $11 / 12(91,6 \%)$ true positive samples (Supplemental Table S2).

\section{Colorimetric RT-LAMP can be performed on clinical samples without RNA extraction}

RT-LAMP performed in clinical samples, without any chemical or physical pre-treatment or RNA extraction, returned positive with three out of five positive samples (Figure 7A). In this 
medRxiv preprint doi: https://doi.org/10.1101/2021.05.26.21257488; this version posted June 2, 2021. The copyright holder for this preprint (which was not certified by peer review) is the author/funder, who has granted medRxiv a license to display the preprint in perpetuity. It is made available under a CC-BY-NC-ND 4.0 International license .

assay we used laboratory-cultured and inactivated SARS-CoV-2 and clinical samples without previous RNA extraction, showing that it is possible to use direct patients' samples without preprocessing (Figure 7A). However, this should be taken with caution, as crude clinical samples may contain interferents. Previous heat-inactivation can be used to reduce this possibility. Here, only 1 $\mu \mathrm{L}$ of 1:10 solution of hydrochloride guanidine-containing VTM from nasopharyngeal swabs was added as a template to the SARS-CoV-2 LAMP reaction. Further analyses are being performed to establish the method sensitivity and feasibility for massive patient screening. All five samples had had previous RNA extraction, for RT-PCR analysis, supporting that extraction process can increase detection sensitivity. We also tested the incubation time at $65{ }^{\circ} \mathrm{C}$ reaction temperature. All SARS-CoV-2 control samples turned reaction color from fuchsia to yellow as indicative of DNA amplification, confirming positive reaction from the earliest time point tested (Figure 7B). In all tested intervals non-template controls were pink/fuchsia (negative) as expected, without any spurious late amplification, as confirmed by agarose gel electrophoresis showing no amplification bands on it (Fig 7B).

A

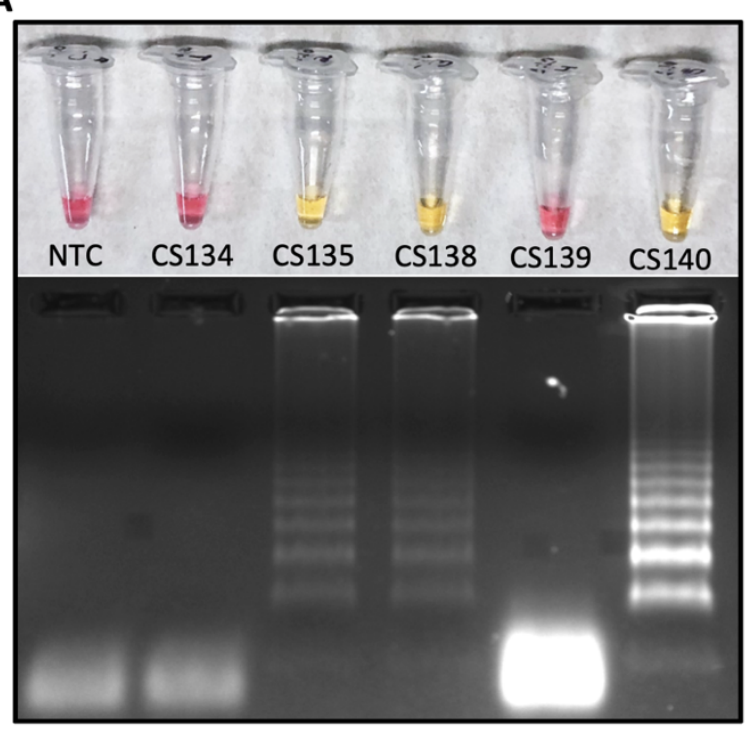

B

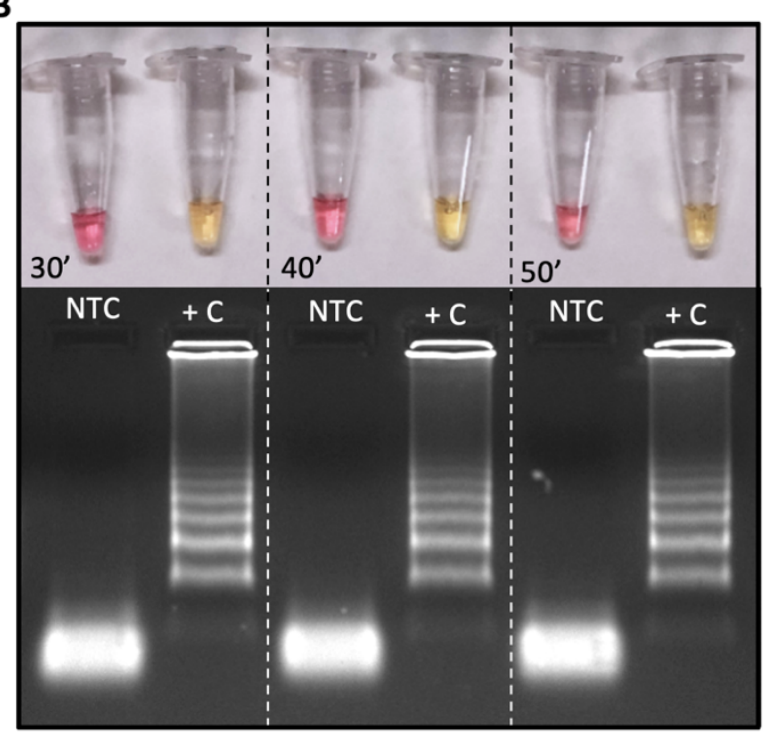

Figure 7 - Colorimetric RT-LAMP to detect SAR-CoV-2 in RNA extraction-free clinical samples (A) or laboratory-cultured virus (B). Clinical samples were derived from nasopharyngeal swabs placed on guanidinecontaining viral transport medium, diluted 1:10. The RT-PCR Ct values for SARS-CoV-2 based on E gene are: $\mathrm{CS} 134=31.8 ; \mathrm{CS} 135=15.3 ; \mathrm{CS} 138=18.4 ; \mathrm{CS} 139=21.7$ and CS140 $=24.6$. RT-LAMP reaction was performed in $20 \mu \mathrm{L}$ final volume, incubated at $65^{\circ} \mathrm{C}$ during 30,40 or 50 min (inactivated virus) using WarmStart ${ }^{\circledR}$ colorimetric LAMP master mix (NEB \#M1800). Both, clinical samples or viruses, are RNA extraction-free samples. The amplification products (amplicons) were migrated in agarose gel at $2 \%$ to confirm amplification, as indicated by the characteristic ladder highlighted by GelRed ${ }^{\circledR}$ staining. NTC: non-template control; CS: clinical sample; $+\mathrm{C}$ : positive control. 
medRxiv preprint doi: https://doi.org/10.1101/2021.05.26.21257488; this version posted June 2, 2021. The copyright holder for this preprint (which was not certified by peer review) is the author/funder, who has granted medRxiv a license to display the preprint in perpetuity. It is made available under a CC-BY-NC-ND 4.0 International license .

\section{Colorimetric RT-LAMP allows the detection of new SARS-CoV-2 variants of interest (VOI) and concern (VOC)}

As a worldwide concern, SARS-CoV-2 VOI and VOCs molecular detection could fail when applying S region-based RT-qPCR diagnostic methods due to mutations that would prevent primer annealing. In order to provide experimental evidences that RT-LAMP as a powerful molecular tool for detecting SARS-CoV-2 RNA, including VOC and VOI, we performed the tests on clinical samples that were previously identified as VOC/VOI by complete genome sequencing. All tested variants, including P.1 (B.1.1.28.1) and P.2 (B.1.1.28.2) - originally reported in Brazil - were detected in colorimetric SARS-CoV-2 RT-LAMP (Figure 8), either by N gene alone as target or by multiplex strategy using N2/E1 primer set, indicating that none of the mutant polymorphisms prevents specific primer annealing on RT-LAMP COVID-19 diagnosis (Figure 8).
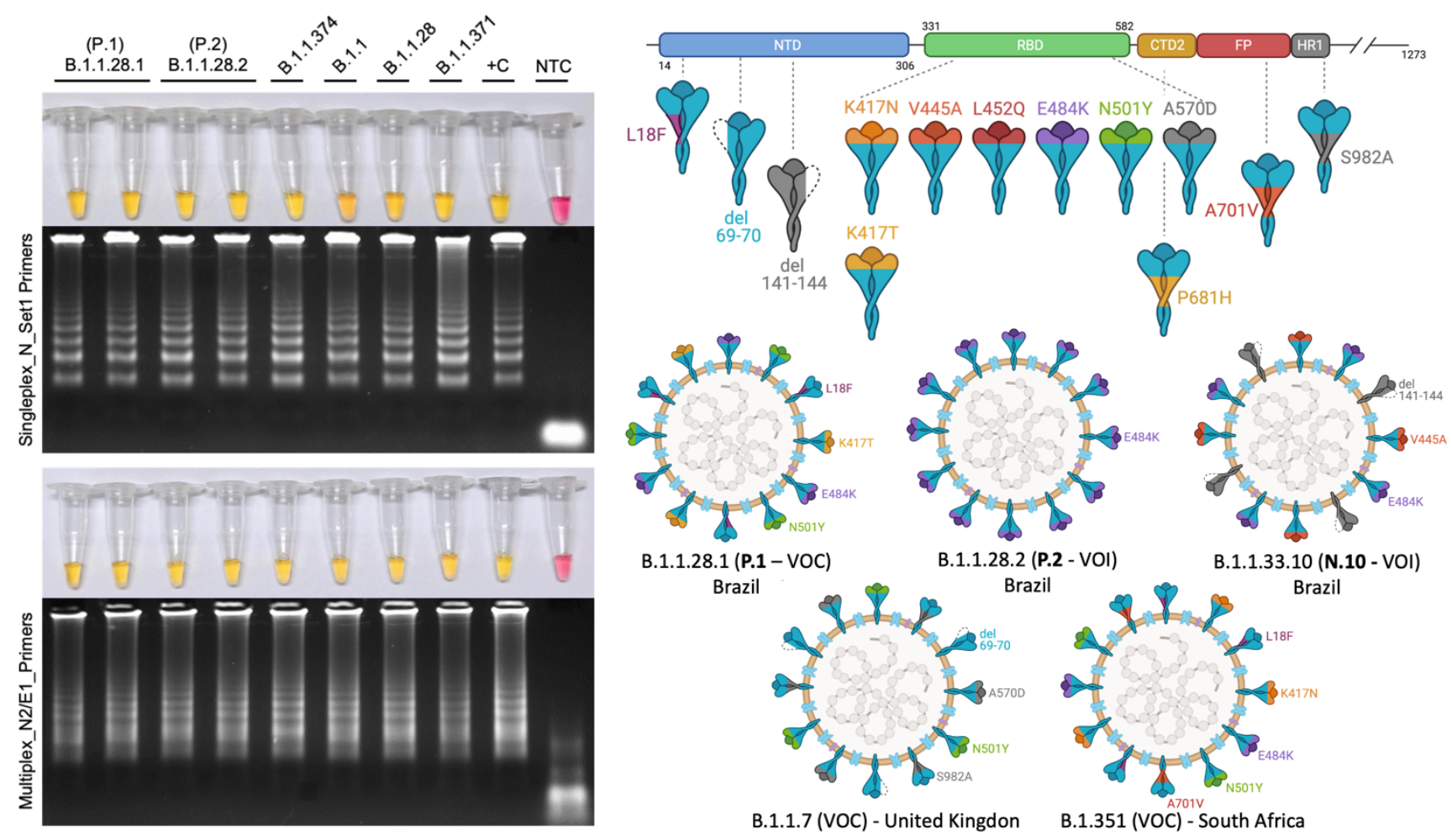

Figure 8 - Colorimetric RT-LAMP allows the detection of SARS-CoV-2 variants of concern (VOC) and interest (VOI). RT-LAMP reaction was performed at $65^{\circ} \mathrm{C}$ for $30 \mathrm{~min}$, using the WarmStart ${ }^{\circledR}$ colorimetric LAMP 2x master mix (NEB \#M1804), using either SARS-CoV-2 N gene set1 primers (upper left panel) or multiplex N2/E1 primer sets (down left panel). The amplicons were migrated in agarose gel at $2 \%$ to confirm amplification, as indicated by the characteristic ladder highlighted by GelRed ${ }^{\circledR}$ staining. NTC: non-template control; CS: clinical sample; +C: positive control. The right hand panel shows a schematic representation of SARS-CoV-2 spike protein (upper) and highlights as representative SARS-CoV-2 virions, the main marker mutations present in Brazilian VOC P.1, VOI P.2 and N.10 as well as the VOC B.1.1.7 and B1.3.51 firstly reported in the United Kingdom and South Africa, respectively. K417N: lysine to asparagine substitution at position 417 of spike protein at the receptor biding domain (RBD); V445A: valine to alanine substitution at position 445 and so on. L: Leucine; Q: glutamine; E: glutamic acid; Y: tyrosine; T: threonine; P: proline; H: histidine; D: aspartic acid; S: serine; F: phenylalanine. del: deletion. Segments of SARS-CoV-2 protein 
medRxiv preprint doi: https://doi.org/10.1101/2021.05.26.21257488; this version posted June 2, 2021. The copyright holder for this preprint (which was not certified by peer review) is the author/funder, who has granted medRxiv a license to display the preprint in perpetuity. It is made available under a CC-BY-NC-ND 4.0 International license .

NTD: N-terminal domain; CTD2: C-terminal domain 2 or C terminus of S1 fragment after furin cleavage; FP: fusion peptide; HR1: heptad repeat region 1. SARS-CoV-2 variants were previously sequenced. Variants of interest B.1.1.371 and B.1.1.374 were first reported in Saudi Arabia and Finland, respectively (https://cov-lineages.org/).

\section{DISCUSSION}

The COVID-19 pandemics demanded a rapid global response in massive diagnostic solution to face the worldwide crisis. In this context, the RT-qPCR - considered the gold-standard technique for SARS-CoV-2 RNA detection - requires high-cost equipments, trained personnel and specialized laboratory structure. In addition, during COVID-19 pandemics, several health care centers and private laboratories competed for RT-qPCR kits and related products to meet the high diagnostic demand. In order to overcome the lacking of molecular testing and provide affordable alternatives, RT-LAMP had become one of the main hopes. Due to its simplicity, accuracy comparable with RT-qPCR to detect SARS-CoV-2 RNA, does not require PCR machine and naked eye readable colorimetric output, RT-LAMP was the focus of massive testing campaigns $(14,16,28)$. This screening strategy is compatible with: home, primary care clinics, point of entry (borders), schools, universities, sport leagues, companies and can help to achieve a safe back to work and quarantine monitoring $(10,14,16,28,30)$. Since April $14^{\text {th }}, 2020$ the U.S. Food and Drugs Administration (FDA) issued the emergence use authorization of Color SARS-CoV-2 RT-LAMP Diagnostic Assay from Color Health, Inc. (EUA number: EUA200539).

In order to provide an affordable SARS-CoV-2 detection tools, we validate a colorimetric RT-LAMP for the COVID-19 diagnosis using clinical samples collected from different parts of Brazil. The country has a flawed screening performance, testing less than 220 individuals per 1,000 people (May 2021) (https://www.worldometers.info/coronavirus) where the majority of tests rely on antibodies-based rapid tests which are not the most reliable and recommended for mass screening and decision making to control local outbreaks. The test sensitivity of RT-LAMP, which is comparable to gold standard RT-qPCR and clearly relies on: the target choice, incubation time, viral load (asymptomatic patients, days of symptoms, correct sampling), output reading, sample integrity and quality (viral transport media, sample storage condition, pre-analytical treatments, extraction procedure, crude RNA extraction free samples) and sample type (nasal, nasopharyngeal, saliva, sputum, gargle lavage) (Table 2). 
Table 2 - Comparison of SARS-CoV-2 RT-LAMP solutions, including key parameters on clinical validation.

\begin{tabular}{|c|c|c|c|c|c|c|c|c|c|c|c|c|}
\hline $\begin{array}{l}\text { Comercial } \\
\text { name or } \\
\text { Acronym }\end{array}$ & Sample source & $\begin{array}{l}\text { Transport } \\
\text { medium }\end{array}$ & Target & $\begin{array}{l}\text { Internal } \\
\text { control }\end{array}$ & $\begin{array}{l}\text { RNA } \\
\text { extraction }\end{array}$ & $\begin{array}{l}\text { Kit/ } \\
\text { Output }\end{array}$ & Program & $\begin{array}{l}\text { Sensitivity/ } \\
\text { Specificity }\end{array}$ & LoD & $\begin{array}{l}\text { Clinical } \\
\text { sample } \\
\text { tested }\end{array}$ & Local & Ref. \\
\hline \multirow[t]{6}{*}{ OmniLAMP } & Nasopharyngeal & VTM & $\begin{array}{l}N, E \text { and } \\
R d R p \\
\text { genes }\end{array}$ & NA & Yes & $\begin{array}{l}\text { NEB \#M1800; } \\
\text { \#M1804 } \\
\text { Color }\end{array}$ & $\begin{array}{l}65^{\circ} \mathrm{C} / \\
30 \mathrm{~min}\end{array}$ & $\begin{array}{l}100 \% / 100 \% \\
\text { Up to RT- } \\
\text { qPCR Ct value } \\
30\end{array}$ & $\begin{array}{l}20 \mathrm{cps} / \mu \mathrm{L} \\
\text { using clinical } \\
\text { samples }\end{array}$ & 100 & $\begin{array}{l}\text { CT-Vacinas- } \\
\text { Fiocruz/UFMG, } \\
\text { Belo Horizonte, } \\
\text { Brazil }\end{array}$ & This study \\
\hline & \multirow[t]{2}{*}{ Nasopharyngeal } & \multirow[t]{2}{*}{ Saline } & \multirow{2}{*}{$\begin{array}{l}N \text { gene } \\
\text { and } \\
\text { ORF1a }\end{array}$} & \multirow{2}{*}{$\begin{array}{l}\text { Human } \\
\text { actin B } \\
\text { gene }\end{array}$} & No & \multirow{2}{*}{$\begin{array}{l}\text { NEB \#M1800 } \\
\text { Color }\end{array}$} & \multirow{2}{*}{$\begin{array}{l}65^{\circ} \mathrm{C} / \\
30 \mathrm{~min}\end{array}$} & $87.5 \% / 100 \%$ & $25 \mathrm{cps} / \mu \mathrm{L}$ & 62 & \multirow{2}{*}{$\begin{array}{l}\text { Massachusetts } \\
\text { General } \\
\text { Hospital, } \\
\text { Boston, MA, } \\
\text { USA }\end{array}$} & \multirow{2}{*}{$\begin{array}{l}\text { Anahtar et } \\
\text { al. } 2021 \text { (9) }\end{array}$} \\
\hline & & & & & Yes & & & $90 \% / 100 \%$ & & 40 & & \\
\hline & NI & NI & $\begin{array}{l}N \text { gene; } \\
\text { ORF1ab }\end{array}$ & NI & Yes & $\begin{array}{l}\text { NEB \#M1800 } \\
\text { Color }\end{array}$ & $\begin{array}{l}65^{\circ} \mathrm{C} / \\
30 \mathrm{~min}\end{array}$ & $100 \% / 100 \%$ & $240 \mathrm{cps} / \mathrm{Rx}$ & 62 & $\begin{array}{l}\text { Paraná Central } \\
\text { Laboratory, } \\
\text { Curitiba, Brazil }\end{array}$ & $\begin{array}{l}\text { Aoki et al. } \\
2021 \text { (34) }\end{array}$ \\
\hline & Saliva & NA & $N$ gene & NI & No, heated & NI & $\begin{array}{l}63^{\circ} \mathrm{C} / \\
30 \mathrm{~min}\end{array}$ & $78.9 \% / 100 \%$ & NI & 244 & $\begin{array}{l}\text { Sírio-Libanês } \\
\text { Hospital, São } \\
\text { Paulo, Brazil }\end{array}$ & $\begin{array}{l}\text { Asprino et } \\
\text { al. } 2020(35)\end{array}$ \\
\hline & Nasal & NI & $N$ gene & NI & Yes & $\begin{array}{l}\text { NEB \#M1800 } \\
\text { Color }\end{array}$ & $\begin{array}{l}65^{\circ} \mathrm{C} / \\
30 \mathrm{~min}\end{array}$ & NI & $\begin{array}{l}10^{-7} \\
\text { (equivalent } \\
\text { to Ct } 34 \text { in } \\
\text { RT-PCR) }\end{array}$ & 14 & $\begin{array}{l}\text { National } \\
\text { Medical Center, } \\
\text { Republic of } \\
\text { Korea }\end{array}$ & $\begin{array}{l}\text { Baek et al. } \\
2020 \text { (17) }\end{array}$ \\
\hline \multirow[t]{2}{*}{ ALERT } & Nasal, saliva & PBS & $N$ gene & $\begin{array}{l}\text { BPIFA1 } \\
\text { gene }\end{array}$ & $\begin{array}{l}\text { Yes or } \\
\text { without } \\
\text { extraction } \\
\text { (Lysate } \\
\text { samples) }\end{array}$ & $\begin{array}{l}\text { NEB Bst } 3.0 \\
\text { and RTx; } \\
\text { \#M1800 } \\
\text { Fluorescence }\end{array}$ & $\begin{array}{l}63^{\circ} \mathrm{C} / \\
45 \mathrm{~min}\end{array}$ & $95 \% / 97-100 \%$ & $2 \mathrm{cps} / \mu \mathrm{L}$ & 47 & $\begin{array}{l}\text { Hôpital Saint } \\
\text { Louis, Paris, } \\
\text { France; Pontifica } \\
\text { Universidad } \\
\text { Católica, } \\
\text { Santiago, Chile }\end{array}$ & $\begin{array}{l}\text { Bektas et al. } \\
2021 \text { (29) }\end{array}$ \\
\hline & $\begin{array}{l}\text { Throat and } \\
\text { nasopharyngeal }\end{array}$ & UTM & $N$ gene; & NI & $\begin{array}{l}\text { No } \\
\text { (Lysate } \\
\text { samples) }\end{array}$ & NEB \#M1800 & $\begin{array}{l}65^{\circ} \mathrm{C} / \\
30-40 \\
\min \end{array}$ & $\begin{array}{l}71.15 \% / 96.77 \% \\
(30 \mathrm{~min}) \\
76,9 \% / 96 / 77 \% \\
(35 \text { or } 40 \mathrm{~min})\end{array}$ & NI & 180 & $\begin{array}{l}\text { Rambam Health } \\
\text { Care Campus, } \\
\text { Haifa, Israel }\end{array}$ & $\begin{array}{l}\text { Ben-Assa et } \\
\text { al. } 2020 \text { (36) }\end{array}$ \\
\hline LAMP-OSD & $\begin{array}{l}\text { Naso and } \\
\text { oropharyngeal } \\
\text { and } \\
\text { SARS-CoV-2 } \\
\text { spiked saliva }\end{array}$ & & $\begin{array}{l}N \text { gene; } \\
\text { ORF1ab } \\
(N S P 3 \text { and } \\
\text { RdRp } \\
\text { genes) }\end{array}$ & NI & Yes & $\begin{array}{l}\text { NEB Bst } 2.0 \\
\text { polymerase; } \\
\text { WarmStart } \\
\text { RTx + Betaine } \\
\text { and additional } \\
\mathrm{MgCl}_{2} \\
+ \text { FAM } \\
\text { Fluorescence }\end{array}$ & $\begin{array}{l}65^{\circ} \mathrm{C} / \\
90 \mathrm{~min}\end{array}$ & NI & $10 \mathrm{cps} / \mathrm{Rx}$ & NA & NA & $\begin{array}{l}\text { Bhadra et al. } \\
2020 \text { (37) }\end{array}$ \\
\hline \multirow[t]{2}{*}{ Cap-iLAMP } & Gargle lavage & NA & $\begin{array}{l}N \text { gene; } \\
\text { ORFlab }\end{array}$ & & $\begin{array}{l}\text { No, heated } \\
\text { samples }\end{array}$ & $\begin{array}{l}\text { NEB \#M1800 } \\
\text { Color + } \\
\text { SYTO9 } \\
\text { Fluorescence }\end{array}$ & $\begin{array}{l}65^{\circ} \mathrm{C} / \\
25-30 \\
\min \end{array}$ & $97,1 \% /$ & $500 \mathrm{cps} / \mathrm{Rx}$ & 192 & NI & $\begin{array}{l}\text { Bokelman et } \\
\text { al. } 2021 \text { (30) }\end{array}$ \\
\hline & $\begin{array}{l}\text { Naso and } \\
\text { oropharyngeal }\end{array}$ & $\begin{array}{l}\text { BD } \\
\text { UVTM }\end{array}$ & $\begin{array}{l}N \text { gene } \\
\text { and } \\
E \text { gene }\end{array}$ & $\begin{array}{l}\text { Human } \\
\text { actin B } \\
\text { gene }\end{array}$ & Yes & $\begin{array}{l}\text { NEB } \\
\# \text { M1800 }\end{array}$ & $\begin{array}{l}65^{\circ} \mathrm{C} / \\
30-40 \\
\min \end{array}$ & $95.6 \% / 99.2 \%$ & $8 \mathrm{cps} / \mu \mathrm{L}$ & 857 & $\begin{array}{l}\text { New York } \\
\text { Presbyterian } \\
\text { Hospital Weill }\end{array}$ & $\begin{array}{l}\text { Butler et al. } \\
2020 \text { (38) }\end{array}$ \\
\hline
\end{tabular}




\begin{tabular}{|c|c|c|c|c|c|c|c|c|c|c|c|c|}
\hline & & & & & & $\begin{array}{l}\text { Color }+ \\
\text { QuantiFluor } \\
\text { (Fluorescence) }\end{array}$ & & & & & $\begin{array}{l}\text { Cornell Medical } \\
\text { Center, NY, } \\
\text { USA }\end{array}$ & \\
\hline \multirow[t]{4}{*}{$\begin{array}{l}\text { COVID-19- } \\
\text { LAMP }\end{array}$} & $\begin{array}{l}\text { Nasopharyngeal, } \\
\text { spuntum and } \\
\text { throat }\end{array}$ & & $\begin{array}{l}\text { ORF3a, E } \\
\text { gene }\end{array}$ & NI & Yes & $\begin{array}{l}\text { NEB } \\
\text { colorimetric } \\
\text { WarmStart }\end{array}$ & $\begin{array}{l}63^{\circ} \mathrm{C} / \\
60-90 \\
\min \end{array}$ & $98.2 \% / 100 \%$ & $42 \mathrm{cps} / \mathrm{Rx}$ & 223 & $\begin{array}{l}\text { University of } \\
\text { Hong Kong } \\
\text { Hospital, China }\end{array}$ & $\begin{array}{l}\text { Chow et al. } \\
2020 \text { (28) }\end{array}$ \\
\hline & Nasal and oral & PBS & ORF1a & $\begin{array}{l}\text { human } \\
18 \mathrm{~S} \\
\text { RNA }\end{array}$ & Yes & $\begin{array}{l}\text { NEB } \\
\text { colorimetric } \\
\text { WarmStart }\end{array}$ & $\begin{array}{l}63^{\circ} \mathrm{C} / \\
30 \mathrm{~min}\end{array}$ & $93.8 \% / 90.4 \%$ & $\begin{array}{l}100 \mathrm{cps} / \mathrm{Rx} \\
\text { up to } \mathrm{Ct} 35\end{array}$ & 466 & $\begin{array}{l}\text { Erasto Gaertner } \\
\text { Hospital, } \\
\text { Curitiba, PR, } \\
\text { Brazil }\end{array}$ & $\begin{array}{l}\text { Coelho et al. } \\
2021 \text { (39) }\end{array}$ \\
\hline & Nasopharyngeal & SPS & $\begin{array}{l}N \text { gene } \\
\text { and } \\
\text { ORFlab }\end{array}$ & NI & Yes & $\begin{array}{l}\text { NEB Bst 2.0, } \\
3.0, \text { RTx } \\
\text { WarmStart } \\
\text { +EvaGreen } \\
\text { Color and } \\
\text { Fluorescence }\end{array}$ & & $\begin{array}{l}8.3- \\
100 \% / 100 \%\end{array}$ & $200 \mathrm{cps} / \mathrm{Rx}$ & & $\begin{array}{l}\text { University } \\
\text { Hospital of } \\
\text { Salamanca, } \\
\text { Spain }\end{array}$ & $\begin{array}{l}\text { Diego et al. } \\
2021\end{array}$ \\
\hline & Nasopharyngeal & $\begin{array}{l}\text { UTM, } \\
\text { VTM or } \\
\text { PBS }\end{array}$ & ORFla & NI & No & $\begin{array}{l}\text { NEB \#E1700 } \\
\text { Fluorescence }\end{array}$ & $\begin{array}{l}63^{\circ} \mathrm{C} / \\
40 \mathrm{~min}\end{array}$ & $81 \% / 100 \%$ & $62.5 \mathrm{cps} / \mu \mathrm{L}$ & 137 & $\begin{array}{l}\text { University of } \\
\text { Winsconsin - } \\
\text { Madison } \\
\text { Hospital and } \\
\text { Clinics, USA }\end{array}$ & $\begin{array}{l}\text { Dudley et al. } \\
2020 \text { (14) }\end{array}$ \\
\hline \multirow[t]{2}{*}{$\begin{array}{l}\text { Penn-RAMP } \\
\text { RPA+ } \\
\text { LAMP }\end{array}$} & $\begin{array}{l}\text { Nasal (spiked } \\
\text { samples) }\end{array}$ & NA & ORFIab & NI & $\mathrm{NA}$ & $\begin{array}{l}\text { OptiGene } \\
\text { Isothermal } \\
\text { mastermix } \\
\text { (ISO-001)+ } \\
\text { EvaGreen dye } \\
\text { Loopamp® } \\
\text { 2019-SARS- } \\
\text { CoV-2 } \\
\text { Detection } \\
\text { Reagent Kit } \\
\text { (Eiken } \\
\text { Chemical, } \\
\text { Tokyo, Japan) } \\
\text { + Leuco } \\
\text { Crystal Violet }\end{array}$ & $\begin{array}{l}63^{\circ} \mathrm{C} / \\
50 \mathrm{~min}\end{array}$ & $100 \% / \mathrm{NI}$ & $7 \mathrm{cps} / \mathrm{Rx}$ & NA & NA & $\begin{array}{l}\text { El-Tholoth } \\
\text { et al. } 2020 \\
\text { (16) }\end{array}$ \\
\hline & $\begin{array}{l}\text { Saliva; Throat } \\
\text { and Nasal }\end{array}$ & VTM & $N$ gene & NI & $\begin{array}{l}\text { No, chelating } \\
\text { agent } \\
\text { treatment }\end{array}$ & $\begin{array}{l}\text { NEB } \\
\text { Color }\end{array}$ & $\begin{array}{l}65^{\circ} \mathrm{C} / \\
30 \mathrm{~min}\end{array}$ & $90 \% 100 \%$ & $10^{5} \mathrm{cps} / \mathrm{mL}$ & 62 & $\begin{array}{l}\text { Rambam Health } \\
\text { Care Campus in } \\
\text { Haifa, Israel }\end{array}$ & $\begin{array}{l}\text { Flynn et al. } \\
2020(40)\end{array}$ \\
\hline \multirow[t]{2}{*}{$\begin{array}{l}\text { OptiGene } \\
\text { COVID-19 } \\
\text { RT-LAMP }\end{array}$} & Nasopharyngeal & VTM & ORFla & NI & $\begin{array}{l}\text { Yes; and also } \\
\text { tested } \\
\text { without } \\
\text { RNA } \\
\text { extraction }\end{array}$ & $\begin{array}{l}\text { OptiGene } \\
\text { GspSSD } 2.0 \\
\text { Opti-RT } \\
\text { Fluorescence }\end{array}$ & $\begin{array}{l}65^{\circ} \mathrm{C} / \\
20 \mathrm{~min}\end{array}$ & $97 \% / 99 \%$ & $\begin{array}{l}100-200 \\
\mathrm{cps} / \mathrm{Rx}\end{array}$ & 196 & $\begin{array}{l}\text { Hampshire } \\
\text { Hospitals NHS } \\
\text { Foundation } \\
\text { Trust, UK }\end{array}$ & $\begin{array}{l}\text { Fowler et al. } \\
2020(41)\end{array}$ \\
\hline & Nasopharyngeal & VTM & $\begin{array}{l}\text { ORF1a, } \\
\text { ORF } 8, S \\
\text { and } N \\
\text { genes }\end{array}$ & & No & $\begin{array}{l}\text { NEB Bst } 2.0 \\
+ \text { EvaGreen } \\
\text { Fluorescence }\end{array}$ & $\begin{array}{l}65^{\circ} \mathrm{C} / \\
60 \mathrm{~min}\end{array}$ & $100 \% / 100 \%$ & $50 \mathrm{cps} / \mu \mathrm{L}$ & 20 & $\begin{array}{l}\text { OSF Healthcare. } \\
\text { Peoria, IL, USA }\end{array}$ & $\begin{array}{l}\text { Ganguli et } \\
\text { al. } 2020 \text { (42) }\end{array}$ \\
\hline
\end{tabular}




\begin{tabular}{|c|c|c|c|c|c|c|c|c|c|c|c|c|}
\hline & Nasopharyngeal & NI & $N$ gene & NI & Yes & $\begin{array}{l}\text { NEB \#M1800 } \\
\text { Color } \\
\text { +EvaGreen } \\
\text { Fluorescence }\end{array}$ & $\begin{array}{l}65^{\circ} \mathrm{C} / \\
50 \mathrm{~min}\end{array}$ & NI & $625 \mathrm{cps} / \mathrm{Rx}$ & 14 & $\begin{array}{l}\text { Hospital Alfa } \\
\text { Medical Center, } \\
\text { Guadalupe, } \\
\text { México }\end{array}$ & $\begin{array}{l}\text { González- } \\
\text { González et } \\
\text { al. } 2021 \text { (43) }\end{array}$ \\
\hline & Throat & VTM & $\begin{array}{l}\text { ORFlab, } \\
S \text { gene } \\
\text { and } N \\
\text { gene }\end{array}$ & $\begin{array}{l}\text { Human } \\
\text { actin B } \\
\text { gene }\end{array}$ & Yes & $\begin{array}{l}\text { NEB \#M1800 } \\
\text { Color }\end{array}$ & $\begin{array}{l}65^{\circ} \mathrm{C} / \\
30 \mathrm{~min}\end{array}$ & NI & $2 \mathrm{cps} / 25 \mu \mathrm{L}$ & 16 & $\begin{array}{l}\text { Shenzhen Luohu } \\
\text { People's } \\
\text { Hospital in } \\
\text { China. }\end{array}$ & $\begin{array}{l}\text { Huang et al. } \\
2020(44)\end{array}$ \\
\hline & Nasopharyngeal & $\begin{array}{l}\text { BD } \\
\text { UVTM }\end{array}$ & NI & NI & Yes & $\begin{array}{l}\text { SARS-CoV-2 } \\
\text { detection kit } \\
\text { (Eiken } \\
\text { Chemical Co.) } \\
\text { Turbidimetry } \\
\text { Fluorescence }\end{array}$ & $\begin{array}{l}62.5^{\circ} \mathrm{C} \\
/ 35 \mathrm{~min}\end{array}$ & $56.6 \% / 98.4 \%$ & $6.7 \mathrm{cps} / \mathrm{Rx}$ & 124 & $\begin{array}{l}\text { University } \\
\text { Hospital, Japan }\end{array}$ & $\begin{array}{l}\text { Inaba et al. } \\
2021 \text { (45) }\end{array}$ \\
\hline & Nasopharyngeal & NI & $\mathrm{NI}$ & NI & Yes & $\begin{array}{l}\text { Loopamp® } \\
\text { 2019-SARS- } \\
\text { CoV-2 } \\
\text { Detection } \\
\text { Reagent Kit } \\
\text { (Eiken } \\
\text { Chemical, } \\
\text { Tokyo, Japan) }\end{array}$ & $\begin{array}{l}62.5^{\circ} \mathrm{C} / \\
35 \mathrm{~min}\end{array}$ & $100 \% / 97.6 \%$ & $101 \mathrm{cps} / \mu \mathrm{L}$ & 76 & $\begin{array}{l}\text { National } \\
\text { Institute of } \\
\text { Infectious } \\
\text { Diseases, Japan }\end{array}$ & $\begin{array}{l}\text { Kitagawa et } \\
\text { al. } 2020 \text { (46) }\end{array}$ \\
\hline & & & & & & Turbidity & & & & & & \\
\hline \multirow[t]{4}{*}{ EasyCOV } & Saliva & VTM & $\mathrm{NI}$ & NI & No & $\begin{array}{l}\text { NEB E1700 + } \\
1 \mathrm{M} \text { Betaine/ } \\
\text { Flourescence }\end{array}$ & $\begin{array}{l}65^{\circ} \mathrm{C} / \\
30 \mathrm{~min}\end{array}$ & $72.7 \% / 95.7 \%$ & $\begin{array}{l}\text { Equivalent to } \\
\text { Ct } 35 \text { in RT- } \\
\text { PCR }\end{array}$ & 123 & $\begin{array}{l}\text { Montpellier } \\
\text { University } \\
\text { Hospital, France }\end{array}$ & $\begin{array}{l}\text { L'Helgouach } \\
\text { et al. } 2020 \\
(27)\end{array}$ \\
\hline & Saliva & Saline & $N$-A gene & NI & $\begin{array}{l}\text { No, } \\
\text { Heat }+ \\
\text { Prot. K lysis }\end{array}$ & $\begin{array}{l}\text { NEB \#M1800 } \\
\text { Color }\end{array}$ & $\begin{array}{l}62.5^{\circ} \mathrm{C} / \\
30-60 \\
\min \end{array}$ & NI & $\begin{array}{l}<10 \mathrm{cps} / \mu \mathrm{L} \\
(200 \mathrm{cps} / \mathrm{Rx})\end{array}$ & 5 & $\begin{array}{l}\text { Washington } \\
\text { University } \\
\text { School of } \\
\text { Medicine; } \\
\text { Barnes-Jewish } \\
\text { Hospital; the } \\
\text { Institute of } \\
\text { Clinical and } \\
\text { Translational } \\
\text { Sciences;Tissue } \\
\text { Procurement } \\
\text { Core, USA }\end{array}$ & $\begin{array}{l}\text { Lalli et al. } \\
2021 \text { (47) }\end{array}$ \\
\hline & Throat & NI & $N$ gene & NI & Yes & $\begin{array}{l}\text { NEB Bst 3.0; } \\
\text { WarmStart } \\
\text { RTx; Q5 HF } \\
\text { DNA } \\
\text { polymerase } \\
\text { Color or } \\
\text { Fluorescence }\end{array}$ & $\begin{array}{l}62.5^{\circ} \mathrm{C} / \\
30-40 \\
\min \end{array}$ & $\begin{array}{l}\text { Sensitivity was } \\
100 \% \text { for } 393 \\
\mathrm{cps} / \mathrm{Rx} \\
80 \% \text { for } 79 \\
\mathrm{cps} / \mathrm{Rx} \text { and } \\
60 \% \text { for } 16 \\
\mathrm{cps} / \mathrm{Rx}\end{array}$ & $\begin{array}{l}118.6 \mathrm{cps} / 25 \\
\mu \mathrm{L} \\
\text { or } \\
4.7 \mathrm{cps} / \mu \mathrm{L}\end{array}$ & 56 & $\begin{array}{l}\text { Nantong Third } \\
\text { Hospital, China }\end{array}$ & $\begin{array}{l}\text { Lu et al. } \\
2020(48)\end{array}$ \\
\hline & $\begin{array}{l}\text { Nasopharyngeal } \\
\text { and throat }\end{array}$ & NI & $R d R p$ & NI & Yes & $\begin{array}{l}\text { NEB \#M1800 } \\
\text { Color }\end{array}$ & $\begin{array}{l}65^{\circ} \mathrm{C} / \\
60 \mathrm{~min}\end{array}$ & $95.74 \% / 99.95 \%$ & $25 \mathrm{cps} / \mathrm{Rx}$ & 2120 & $\begin{array}{l}\text { Ramathibodi } \\
\text { Hospital, } \\
\text { Mahidol } \\
\text { University, }\end{array}$ & $\begin{array}{l}\text { Nawattanapa } \\
\text { iboon et al. } \\
2021(49)\end{array}$ \\
\hline
\end{tabular}




\begin{tabular}{|c|c|c|c|c|c|c|c|c|c|c|c|c|}
\hline & & & & & & & & \multirow[b]{2}{*}{$80 \% / 100 \%$} & \multirow{2}{*}{$\begin{array}{l}\text { Not } \\
\text { determined }\end{array}$} & \multirow[b]{2}{*}{21} & \multicolumn{2}{|l|}{ Thailand } \\
\hline & Nasopharyngeal & VTM & ORFlab & NI & $\begin{array}{l}\text { Yes, } \\
\text { Magnetic } \\
\text { bead } \\
\text { extraction }\end{array}$ & $\begin{array}{l}\text { MicrosensDx } \\
\text { RapiPrep }^{\circledR}\end{array}$ & $\begin{array}{l}65^{\circ} \mathrm{C} / \\
25 \mathrm{~min}\end{array}$ & & & & $\begin{array}{l}\text { National Health } \\
\text { Service Care } \\
\text { Home, UK }\end{array}$ & $\begin{array}{l}\text { Osterdahl et } \\
\text { al. } 2020(50)\end{array}$ \\
\hline & $\begin{array}{l}\text { SARS-CoV-2 } \\
\text { isolated from } \\
\text { MRC-5 infected } \\
\text { cells }\end{array}$ & NA & $\begin{array}{l}N S P 3 \\
\text { gene } \\
(O R F 1 a b) \\
S \text { gene; } \\
N \text { gene }\end{array}$ & NI & Yes & $\begin{array}{l}\text { NEB Bst 3.0; + } \\
\text { SuperScript IV } \\
\text { RT Invitrogen } \\
+ \\
\text { or leuco crystal } \\
\text { violet } \\
\text { Color }\end{array}$ & $\begin{array}{l}69^{\circ} \mathrm{C} \text { or } \\
65^{\circ} \mathrm{C} / 30 \\
\text { or } 60 \mathrm{~min}\end{array}$ & $\mathrm{NI}$ & $\begin{array}{l}100 \mathrm{cps} / \mathrm{Rx} \\
\text { or } \\
10^{-6} \mathrm{RNA} \\
\text { dilution }\end{array}$ & NA & NA & $\begin{array}{l}\text { Park et al. } \\
2020(11)\end{array}$ \\
\hline & & & & & & $\begin{array}{l}\text { NEB \#M1800 } \\
+ \text { SYTO-9 } \\
\text { Fluorescence }\end{array}$ & & & & & & \\
\hline & $\begin{array}{l}\text { Saliva, nasal and } \\
\text { Nasopharyngeal }\end{array}$ & Saline & $\begin{array}{l}\text { ORFlab } \\
(\text { As } 1 / 1 e) \\
\text { ORF1a-C } \\
\text { and } N \\
\text { gene }\end{array}$ & NI & No & $\begin{array}{l}\text { NEB \#M1800 } \\
\text { and \#E1700 } \\
\text { Color and } \\
\text { Fluorescence }\end{array}$ & $\begin{array}{l}65^{\circ} \mathrm{C} / \\
30-60 \\
\min \end{array}$ & $\mathrm{NI}$ & 1 сору $/ \mu \mathrm{L}$ & NA & NA & $\begin{array}{l}\text { Rabe \& } \\
\text { Cepko } 2020 \\
(26)\end{array}$ \\
\hline \multirow[t]{3}{*}{$\begin{array}{l}\text { LAMP- } \\
\text { BEAC }\end{array}$} & $\begin{array}{l}\text { Nasopharyngeal } \\
\text { and saliva }\end{array}$ & $\mathrm{NI}$ & $\begin{array}{l}E, N \\
\text { genes; } \\
\text { Orflab } \\
(\text { Asl/1e); }\end{array}$ & $\begin{array}{l}\text { Human } \\
\text { statherin } \\
\text { mRNA }\end{array}$ & $\begin{array}{l}\text { No, } \\
\text { TCEP/EDTA } \\
\text { and heat } \\
\text { treated }\end{array}$ & $\begin{array}{l}\text { NEB \#E1700 } \\
\text { and labmade } \\
\text { Bst FL } \\
\text { Fluorescence }\end{array}$ & $\begin{array}{l}60-65^{\circ} \mathrm{C} / \\
45 \mathrm{~min}\end{array}$ & $\mathrm{NI}$ & $\begin{array}{l}\text { More than } \\
100 \mathrm{cps} / \mu \mathrm{L}\end{array}$ & 82 & NA & $\begin{array}{l}\text { Sherill-Mix } \\
\text { et al. } 2021 \\
(51)\end{array}$ \\
\hline & \multirow[t]{2}{*}{$\begin{array}{l}\text { Nasal and } \\
\text { Nasopharyngeal }\end{array}$} & $\begin{array}{l}\text { Amies } \\
\text { medium }\end{array}$ & \multirow{2}{*}{$\begin{array}{l}\text { ORFla } \\
\text { and } N \\
\text { gene }\end{array}$} & \multirow[t]{2}{*}{ NI } & Yes & \multirow[t]{2}{*}{$\begin{array}{l}\text { NEB \#M1800 } \\
\text { Color }\end{array}$} & $\begin{array}{l}65^{\circ} \mathrm{C} / \\
30 \mathrm{~min}\end{array}$ & $\begin{array}{l}100 \% / 99.7 \% \text { up } \\
\text { to } \mathrm{Ct} 25\end{array}$ & \multirow{2}{*}{$\begin{array}{l}100 \mathrm{cps} / \mathrm{Rx} \\
\text { or } \\
4 \mathrm{cps} / \mu \mathrm{L}\end{array}$} & 792 & \multirow{2}{*}{$\begin{array}{l}\text { University } \\
\text { Hospital } \\
\text { Heidelberg and } \\
\text { municipal } \\
\text { COVID-19 } \\
\text { testing station, } \\
\text { Germany }\end{array}$} & \multirow[t]{2}{*}{$\begin{array}{l}\text { Thi et al. } \\
2020(52)\end{array}$} \\
\hline & & Dry swab & & & $\begin{array}{l}\text { No, } \\
\text { Heat treated } \\
\text { or directly } \\
\text { included in } \\
\text { LAMP } \\
\text { reaction }\end{array}$ & & $\begin{array}{l}65^{\circ} \mathrm{C} / \\
30 \mathrm{~min}\end{array}$ & $\begin{array}{l}90.5 \% / 99.5 \% \\
\text { up to Ct } 25 \text { in } \\
\text { RT-PCR (hot } \\
\text { swab) } \\
93.8 \% / 94.1 \% \\
\text { up to Ct } 25 \text { in } \\
\text { RT-LAMP } \\
\text { (direct swab) }\end{array}$ & & 235 & & \\
\hline \multirow[t]{3}{*}{$\begin{array}{l}\text { One-pot RT- } \\
\text { LAMP }\end{array}$} & NA & NA & $N$ gene & NA & $\begin{array}{l}\text { pUC57-N } \\
\text { gene } \\
\text { (synthetic) }\end{array}$ & $\begin{array}{l}\text { NEB Bst } 3.0 \\
\text { DNA/RNA } \\
\text { polymerase } \\
+ \text { EvaGreen } \\
\text { +Rox } \\
\text { Fluorescence }\end{array}$ & $\begin{array}{l}59^{\circ} \mathrm{C} / \\
50 \mathrm{~min}\end{array}$ & $\mathrm{NI}$ & $6 \mathrm{cps} / \mu \mathrm{L}$ & NA & NA & $\begin{array}{l}\text { Wang } 2020 \\
(15)\end{array}$ \\
\hline & Nasopharyngeal & VTM & ORFlab & NI & $\mathrm{NO}$ & $\begin{array}{l}\text { NEB \#M1800 } \\
\text { Color }\end{array}$ & $\begin{array}{l}63^{\circ} \mathrm{C} / \\
30 \mathrm{~min}\end{array}$ & $75 \% / 100 \%$ & $\begin{array}{l}2.5 \mathrm{cps} / \mathrm{uL} \\
\text { Spiked } \\
\text { samples on } \\
\text { VTM }\end{array}$ & 20 & $\begin{array}{l}\text { Columbia } \\
\text { University Irving } \\
\text { Medical Center }\end{array}$ & $\begin{array}{l}\text { Wei et al. } \\
2021 \text { (53) }\end{array}$ \\
\hline & $\begin{array}{l}\text { Respiratory } \\
\text { swabs and }\end{array}$ & & $\begin{array}{l}\text { ORFlab } \\
\text { and } S \\
\text { gene }\end{array}$ & NI & Yes & $\begin{array}{l}\text { Loopamp }{ }^{\circledR} \\
\text { 2019-SARS- } \\
\text { CoV-2 }\end{array}$ & $\begin{array}{l}63^{\circ} \mathrm{C} / \\
18-60 \\
\min \end{array}$ & $100 \% / 100 \%$ & $\begin{array}{l}20-110 \\
\operatorname{cps} / \mathrm{Rx}\end{array}$ & 130 & $\begin{array}{l}\text { PLA General } \\
\text { Hospital, } \\
\text { Beijing, China }\end{array}$ & $\begin{array}{l}\text { Yan et al. } \\
2020(12)\end{array}$ \\
\hline
\end{tabular}


bronchoalveolar

lavage fluid
Detection

Reagent Kit

(Eiken

Chemical,

Tokyo, Japan)

Turbidity

or

Fluorescence

(+ calcein)

NEB \#M1800
Color

$65^{\circ} \mathrm{C}$

$\geq 20 \mathrm{~min}$
$89.9 \% / \mathrm{NI}$

$10 \mathrm{cps} / \mu \mathrm{L}$

(detection

threshold of

$60 \mathrm{cps} / \mu \mathrm{L})$;

equivalent to

35-37 Ct in

RT-PCR

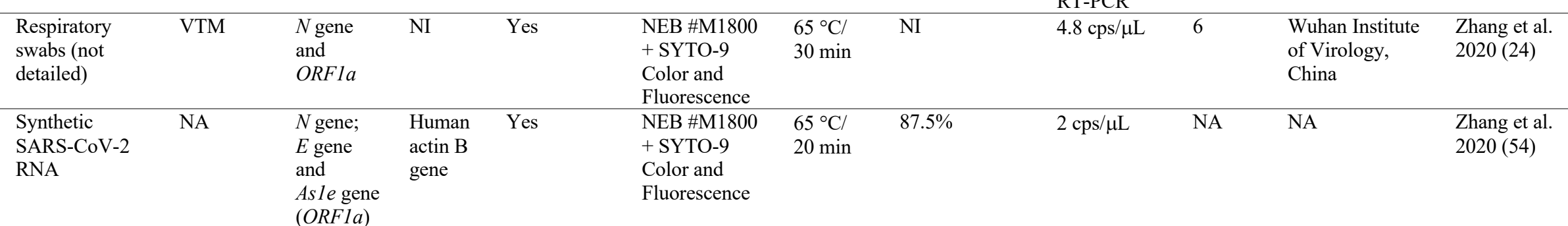

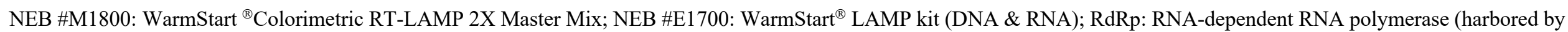

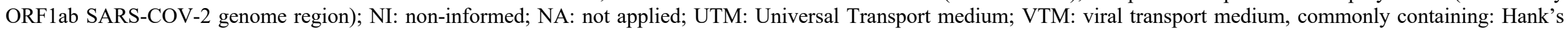

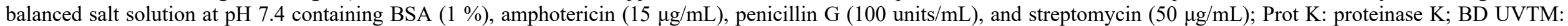

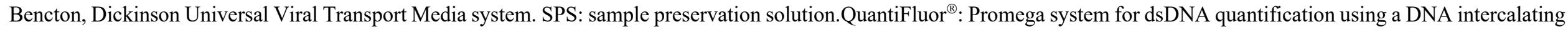

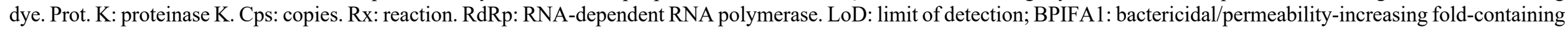
family A1. 
medRxiv preprint doi: https://doi.org/10.1101/2021.05.26.21257488; this version posted June 2, 2021. The copyright holder for this preprint (which was not certified by peer review) is the author/funder, who has granted medRxiv a license to display the preprint in perpetuity. It is made available under a CC-BY-NC-ND 4.0 International license .

Upon RNA extraction from nasopharyngeal swab-derived clinical samples we found a LoD of 20 viral genomic copies $/ \mu \mathrm{L}$, confirming previous studies based on N SARS-CoV-2 target $(9,30,43)$. It is worth noting that when using non-clinical SARS-CoV-2 extracted RNA or synthetic target, the LoD reaches less than $0.5 \mathrm{cps} / \mu \mathrm{L}$. This can be explained by the presence of interferents such as, VTM, host cells and enzymes that could reduce the yield $(14,49)$. In this regard, one has to be careful when interpreting LoD calculated using non-clinical samples. Nevertheless, extracted samples are rich enough in viral genomic copies to meet clinically relevant levels of SARS-CoV2.

Clinical validation of RT-LAMP for COVID-19 diagnosis relies on calculating parameters such as sensitivity, specificity, PPV, NPV and accuracy compared to the gold standard RT-qPCR. We have to be careful when associating the RT-LAMP sensitivity and indirect assumption on RTqPCR viral load is not straightforward due to some technical concerns. It is well accepted that $\mathrm{Ct}$ values can be representative of viral load. However, this parameter could lead to misinterpretation when comparing different kits, targets and non-standardized samples. A survey conducted by the College of American Pathologists on more than 700 laboratories, reported a variation as much as 14 cycles among different methods on the same batch material. Single laboratories using different platforms and targets in SARS-CoV-2 molecular testing can represent a potential variability on Ct-values (55). Considering previous convergent reports and presuming different targets and platforms, the data from the literature shows that with a RT-qPCR Ct 30 cut-off where RT-LAMP sensitivity for SARS-CoV-2 detection is close to 100\% (Ben-Assa et al., 2020; Lamb et al., 2020; L'Helgouach et al., 2020; Smyrlaki et al., 2020; Lalli et al., 2021; Newman et al., 2021; Yang et al., 2021)(39,52,56,57) and eventually with a higher threshold $\mathrm{Ct} 35$ as well $(27,39)$. Indeed, we confirm that up to Ct 30 RT-LAMP returned 100\% sensitivity for SARS-CoV-2 detection, reaching $97 \%$ and $88 \%$ when considering $\mathrm{Ct}$ values up to 32 and 34 respectively. Curiously, Kim and cols. (2021) found that samples from hospitalized patients presenting Ct value of 28.4 or less were infective to cell human culture (58), an evidence - based on in vitro extrapolation - that RTLAMP sensitivity is compatible with threshold of infectivity. This reinforces that simple, robust and reliable RT-LAMP meets clinical requirements, presenting similar COVID-19 diagnostic accuracy as RT-qPCR $(45,50,59)$.

The choice of SARS-CoV-2 genomic target plays an important role when selecting the RTLAMP method for COVID-19 diagnosis. Several research groups have tested different regions on 
medRxiv preprint doi: https://doi.org/10.1101/2021.05.26.21257488; this version posted June 2, 2021. The copyright holder for this preprint (which was not certified by peer review) is the author/funder, who has granted medRxiv a license to display the preprint in perpetuity. It is made available under a CC-BY-NC-ND 4.0 International license .

SARS-CoV-2 genome with the potential to generate RT-LAMP primers. Once, the majority of primers were designed using the open source software Primer Explorer, it is expected that at some point, the default algorithm returned the same result or overlapping regions, independently identified in a context where molecular biology scientists everywhere in the world are working to tackle COVID-19 (Figure 9). According to our data compilation, $N$ gene and ORFlab regions (overlapping NSP3, Asle and RdRp-coding sequences) were the most frequent targets chosen for SARS-CoV-2 RT-LAMP (Table 2 and Figure 9). Ganguli and cols. (2020) and Zhang and cols. (2020) arrived at the same conclusion when selecting the SARS-CoV-2 $N$ gene-targeting primer set after confirming better performances for RNA viral detection when compared to other targets $(42,54)$. When testing $N, E$ and $R d R p$ genes in true positive - previously RT-qPCR characterized clinical samples - we observed more false negative outputs from assays using $E$ and $R d R p$ genes, corroborating what was previously reported. We also highlight that primer subsets within the same $\mathrm{N}$ target gene, can contribute differentially to RT-LAMP test sensitivity (Supplementary Table S2). Furthermore, multiplexing different primer sets is encouraged in order to increase sensitivity (Figure 9) $(54,60,61)$.

Another important (almost) neglected point, is the fact that, although inspired by RT-qPCR target selection, few SARS-CoV-2 RT-LAMP approaches reported an internal control target to confirm the presence of human RNA and monitor sampling or extraction process (39). WilsonDavies and colleagues (2021) pointed out that the lack of amplification can happen for different reasons concerning the whole reaction, a specific well or due to inhibitory substances; highlighting the importance of including internal control even before nucleic acid extraction, in order to be considered a reliable SARS-CoV-2 LAMP assay (62). We have not include internal controls in the clinical validation presented here, since all accessed samples had been previously characterized by RT-qPCR, including human RNAse $\mathrm{P}$ as housekeeping gene. However, in the current OmniLAMP $^{\circledR}$ assay, we included human $\beta$-actin RNA (rACTB) as internal control. Other constitutive targets for SARS-CoV-2 RT-LAMP include BPIFA1 (29), human 18S RNA (39) and Statherin RNA (51) (Table 2).

Similar to its high sensitivity, obtained in our and by other studies, the SARS-CoV-2 RTLAMP specificity is undoubtebly high and is frequently reported as $100 \%$ without any crossreactivity with other respiratory or SARS-CoV unrelated viruses $(11,28,34,49,63)$. We also 
medRxiv preprint doi: https://doi.org/10.1101/2021.05.26.21257488; this version posted June 2, 2021. The copyright holder for this preprint (which was not certified by peer review) is the author/funder, who has granted medRxiv a license to display the preprint in perpetuity. It is made available under a CC-BY-NC-ND 4.0 International license .

confirm that the SARS-CoV-2 RT-LAMP solution presented here is highly specific and does not cross-react with Brazilian occurring seasonal Influenza A and B, hRSV or arboviruses.

Despite the advantages presented by purified and nucleic acid enriched samples for SARSCoV-2 RT-LAMP, RNA extraction-free protocols have attracted attention since they can be noninvasive saliva-based; do not require additional steps and equipment and fulfill point-of-sampling requirements. Indeed, the pre-analytical phase on RT-LAMP is the bottleneck for point-of-care applications. For this reason, several studies highlighted the feasibility of primary RNA extractionfree approaches for SARS-CoV-2 RNA detection $(8,9,14,27,35,36,47,53,57,64)$. Pre-treatment of saliva samples includes heat sample inactivation and the use of lysis/stabilizing buffers that can contain proteinase K, TCEP, EDTA, DTT could help the viral RNA assessment maintaining its integrity $(27,36,47,65-68)$. Caution must be taken when running colorimetric RT-LAMP since pre-treatment could interfere on result outputs. One of the main limitations for direct sample test by colorimetric RT-LAMP based on $\mathrm{pH}$-sensing is the false positive results upon input sample addition (previous to amplification), due to naturally acidic samples $(30,52)$. To prevent spurious amplification due to the presence of DNA from oral microbiome, food or host cells on primary samples, Bokelmann and cols (2021) treated samples with $\lambda$ exonuclease that acts by preferentially digesting 5'-phosphorylated DNA leaving non-phosphorylated primers or LAMP products intact (30). Here we shown preliminary results on RNA extraction-free, pre-treatment free, primary 10x diluted hydrochloride guanidine-containing VTM nasopharyngeal samples directly accessed to compared colorimetric results. Three out of five RT-qPCR true positives directly accessed samples returned positive yellow output on colorimetric RT-LAMP for SARS-CoV-2 detection. This provides clues on the use of unextracted samples for massive COVID-19 testing campaigns with a trade-off on cost-benefits for limit of detection and test sensitivity. Most high and medium viral load samples will be detected on unextracted protocols. However, to meet RT-qPCR detection sensitivity levels, this requires some type of purification step and RNA concentration $(11,24,31)$.

We are currently observing rapid converging evolution of SARS-CoV-2 during COVID19 pandemics worldwide. Several reports alert for the emergence of variants of concern and interests such the B.1.1.7, first detected in England (ECDC - threat assessment brief on December $\left.20^{\text {th }} 2020\right)$ (69); B.1.351 initially reported from South Africa (70); B.1.1.28.1 (P.1) that was identified in Japan but obtained from a traveler from Brazil (33) and more recently the B.1.617.1 and B.1.617.2 VOC detected in India, but that already spread to South America (Argentina's 
medRxiv preprint doi: https://doi.org/10.1101/2021.05.26.21257488; this version posted June 2, 2021. The copyright holder for this preprint (which was not certified by peer review) is the author/funder, who has granted medRxiv a license to display the preprint in perpetuity. It is made available under a CC-BY-NC-ND 4.0 International license .

Health Ministry official report). The regional selection of SARS-CoV-2 VOC is associated with higher transmissibility, mortality and reduced neutralizing antibody response (71-74). In Brazil, we observed the emergence of different SARS-CoV-2 VOC and VOI, including P.1, B.1.28.2 (P.2) $(75,76)$; B.1.1.33.9 (N.9) (77); B.1.1.33.10 (N.10) (78,79). A plethora of mutations is observed in these variants, including N501Y, E484K/Q, K417N/T, A570D and the $\Delta 69-70$ at the SARS-CoV$2 \mathrm{~S}$ protein sequence, which was associated with detection failures by S-target RT-qPCR methods (80). For SARS-CoV-2 RT-LAMP detection, few studies selected S-coding protein region as a target (Figure 9). In addition, isothermal amplification for SARS-CoV-2 RNA detection strategies is commonly addressed as multiplex targeted, making RT-LAMP a good choice even for SARSCoV-2 variants detection. Indeed, here we reported that singleplex $N$ gene-based or multiplex N2/E1-based RT-LAMP was able to perfectly detect VOC and VOI circulating in Brazil such as P.1, P.2, B.1.1.374 and B.1.1.371 (Figure 8), the two latter firstly detected in Finland and Saudi Arabia (https://cov-lineages.org). Recent efforts made by Sherrill-Mix and cols (2021) showed a beacon-based RT-LAMP strategy designed to precisely identify B.1.1.7 SARS-CoV-2 variant $(51,81)$, a promising tool not only for massive screening but also to monitor VOC/VOI SARSCoV-2 spreading.

\section{CONCLUSIONS}

The colorimetric RT-LAMP is a reliable molecular tool for detecting SARS-CoV-2, providing rapid and easy to read results; compatible with high-throughput screenings and pointof-care requirements. This test is especially important for nations with a poor diagnostic conditions, like in Brazil, where RT-qPCR COVID-19 diagnostic is far from ideal to control disease spreading. The RT-LAMP sensitivity can be equivalent to those reported from the gold standard RT-qPCR method and also present 100\% specificity. Results are commonly obtained after $30 \mathrm{~min}$ reaction and if needed, additional $20 \mathrm{~min}$ was not associated with spurious unspecific amplification. Alternative directly accessed samples from diluted guanidine-containing VTM (nasopharyngeal) without any pre-treatment interventions can also be used, however, with lower sensitivity. Sample collection in guanidine-containing VTM has been described as a useful strategy to avoid contamination of health care workers during sample manipulation. RT-LAMP primer selection can directly interfere on sensitivity being $\mathrm{N}$ gene the best target for SARS-CoV-2 RNA detection with less false negative results, especially in low viral load samples. Colorimetric RT- 
medRxiv preprint doi: https://doi.org/10.1101/2021.05.26.21257488; this version posted June 2, 2021. The copyright holder for this preprint (which was not certified by peer review) is the author/funder, who has granted medRxiv a license to display the preprint in perpetuity. It is made available under a CC-BY-NC-ND 4.0 International license .

LAMP is also compatible with detecting SARS-CoV-2 variants of interest and concern, being robust to cope with the monitoring of emerging new SARS-CoV-2 variants and that can be easily adapted. We thus, reinforce and recommend the use of RT-LAMP for massive testing as a decentralized point-of-care alternative for SARS-CoV-2 containment and to tackle COVID-19.

\section{MATERIAL AND METHODS}

\section{Clinical samples, $R T-q P C R$ and ethical statement}

One hundred clinical SARS-CoV-2 samples were obtained from symptomatic hospitalized patients from different parts of Brazil. Nasopharyngeal swabs were collected and maintained in 2 mL VTM (Bioclin, Belo Horizonte, Brazil \#G092-1) at room temperature until RNA extraction or direct dilution for LAMP reaction. The VTM contains guanidine chloride as inactivation agent and to preserve viral RNA. All procedures were performed inside a biosafety level 2 cabinet. RNA extraction was performed using the QIAamp ${ }^{\circledR}$ Viral RNA Mini Kit (Qiagen \#52906), following manufacturer instructions. The molecular diagnostic routine was performed by RT-qPCR using the SARS-CoV-2 commercial kits produced at Fundação Oswaldo Cruz (Kit Molecular SARSCoV-2 E/RP, from Bio-Manguinhos/Fiocruz - based on Charité/Berlin protocol and Kit Biomol OneStep/COVID-19 from IBMP/Fiocruz - based on China/CDC protocol with recommended targets polyprotein ORF1ab and N gene). RT-qPCR was carried out using the 7500, ViiA 7 realtime PCR systems (Applied Biosystems, Foster City, CA. USA) or the dual-channel Open qPCR machine (Chai, Santa Clara, CA, USA), following the temperature program profile of $95^{\circ} \mathrm{C}$ for 3 min, followed by 40 cycles of amplification $\left(95^{\circ} \mathrm{C} / 15 \mathrm{~s}\right.$ and $\left.60{ }^{\circ} \mathrm{C} / 1 \mathrm{~min}\right)$. Influenza and $\mathrm{hRSV}$ samples were kindly provided by IOM/FUNED and the arboviruses samples are part of the collection from the laboratório de Imunologia de Doenças Virais at Oswaldo Cruz Foundation. All procedures involving human participants, collection and use of clinical samples and data were in accordance with ethical standards and approved by the human research ethics committee under license protocol number: 4051614; CAAE (certificate of presentation for ethical appreciation): 31984720300005091. SARS-CoV-2 variants of concern and variants of interest included in this study were isolated from symptomatic patients $(\mathrm{Ct}$ value $<25$, using E gene as target on RT-qPCR - Kit Molecular SARS-CoV-2 E/RP Bio-Manguinhos Fiocruz), in the State Pernambuco, Northeast Brazil (82). 
medRxiv preprint doi: https://doi.org/10.1101/2021.05.26.21257488; this version posted June 2, 2021. The copyright holder for this preprint (which was not certified by peer review) is the author/funder, who has granted medRxiv a license to display the preprint in perpetuity.

\section{RT-LAMP primer design}

RT-LAMP primers were designed based on SARS-CoV-2 reference genome (GenBank accession NC_045512.2) using the open source software Primer Explorer V5 (https://primerexplorer.jp/lampv5e) or the NEB LAMP primer design tool (https://lamp.neb.com). The free energy $(\Delta \mathrm{G})$ of selected primers was less than $-4 \mathrm{kcal} / \mathrm{mol}$, as a parameter chosen based on oligo stability (83). The set of primers used in this study are listed in Table 1 and additional information can be found in Figure 9 and Supplementary Figures S3, S4 and S5. We designed and validated different LAMP primer sets, such as $\mathrm{N}$ gene Set1 and Set2 that appeared in other independent researches (Figure 9 and Table 3). N2 and E1 primer sets were previously designed by Zhang et al. (2020) (54). The oligos were purchased from Integrated DNA technologies (IDT, Coralville, IA, USA) and from Exxtend (Paulínia, SP, Brazil). All oligos were synthesized at 25 nanomole scale and purified by standard desalting. Thermodynamic evaluation of primers targeting SARS-CoV-2 N, E and RdRp genes were performed as previously described (84). Briefly, hybridization temperature of F3, FIP (F1c+F2), BIP (B1c + B2), LF and LB primer sets were calculated upon aligning to SARS-CoV or other coronavirus (non-SARS) genomes, considering potential mismatches. The SARS-CoV-2 coverage for each primer was also obtained (Supplementary Table S1).

Table 3 - Sets of LAMP oligonucleotides used in this study

\begin{tabular}{lll}
\hline LAMP primer & Sequence (5'-3') & Ref. \\
\hline N_Set1_F3 & TGGCTACTACCGAAGAGCT & This study; \\
N_Set1_B3 & TGCAGCATTGTTAGCAGGAT & $(9,16,24,26$ \\
\hline N_Set1_FIP & TCTGGCCCAGTTCCTAGGTAGTGACGAATTCGTGGTGGTGA & $, 36,37,52)$ \\
\hline N_Set1_BIP & AGACGGCATCATATGGGTTGCACGGGTGCCAATGTGATCT & \\
\hline N_Set1_LF & TGGACTGAGATCTTTCATTTTACCG & \\
\hline N_Set1_LB & ACTGAGGGAGCCTTGAATACA & \multirow{2}{*}{ This study; } \\
\hline N_Set2_F3 & TGGACCCCAAAATCAGCG & \\
\hline N_Set2_B3 & GCCTTGTCCTCGAGGGAAT & \\
\hline N_Set2_FIP & CCACTGCGTTCTCCATTCTGGTAAATGCACCCCGCATTACG & \\
\hline N_Set2_BIP & CGCGATCAAAACAACGTCGGCCCTTGCCATGTTGAGTGAGA & \\
\hline N_Set2_LF & TTGAATCTGAGGGTCCACCAAA & \\
\hline N_Set2_LB & GGTTTACCCAATAATACTGCGTCTT & \\
\hline
\end{tabular}


medRxiv preprint doi: https://doi.org/10.1101/2021.05.26.21257488; this version posted June 2, 2021. The copyright holder for this preprint (which was not certified by peer review) is the author/funder, who has granted medRxiv a license to display the preprint in perpetuity.

It is made available under a CC-BY-NC-ND 4.0 International license .

\begin{tabular}{|c|c|c|}
\hline E_Set1_F3 & TGATGAGCCTGAAGAACATG & \multirow[t]{6}{*}{ This study } \\
\hline E_Set1_B3 & CGCTATTAACTATTAACGTACCT & \\
\hline E_Set1_FIP & TCGGTTCATCATAAATTGGTTCCATCAAATTCACACAATCGACGG & \\
\hline E_Set1_BIP & ACGACTACTAGCGTGCCTTTGTCTCTTCCGAAACGAATG & \\
\hline E_Set1_LF & ACTGGATTAACAACTCCGGATGA & \\
\hline E_Set1_LB & GTAAGCACAAGCTGATGAGTACGAA & \\
\hline RdRp_F3 & CTGTCAAATTACAGAATAATGAGC & \multirow[t]{6}{*}{ This study } \\
\hline RdRp_B3 & TCCATCACTCTTAGGGAATC & \\
\hline RdRp_FIP & TGTCATCAGTGCAAGCAGTTTGCTGTTGCACTACGACAGA & \\
\hline RdRp_BIP & ATGCGTTAGCTTACTACAACACACCCATTTCAAATCCTGTAAATCG & \\
\hline RdRp_LF & ACCGGCAGCACAAGACA & \\
\hline RdRp_LB & ACAAAGGGAGGTAGGTTTGTACT & \\
\hline N2_F3 & ACCAGGAACTAATCAGACAAG & \multirow[t]{6}{*}{$(38,54)$} \\
\hline N2_B3 & GACTTGATCTTTGAAATTTGGATCT & \\
\hline N2_FIP & TTCCGAAGAACGCTGAAGCGGAACTGATTACAAACATTGGCC & \\
\hline N2_BIP & CGCATTGGCATGGAAGTCACAATTTGATGGCACCTGTGTA & \\
\hline N2_LF & GGGGGCAAATTGTGCAATTTG & \\
\hline N2_LB & CTTCGGGAACGTGGTTGACC & \\
\hline E1_F3 & TGAGTACGAACTTATGTACTCAT & \multirow[t]{6}{*}{$(38,54)$} \\
\hline E1_B3 & TTCAGATTTTTAACACGAGAGT & \\
\hline E1_FIP & ACCACGAAAGCAAGAAAAAGAAGTTCGTTTCGGAAGAGACAG & \\
\hline E1_BIP & TTGCTAGTTACACTAGCCATCCTTAGGTTTTACAAGACTCACGT & \\
\hline E1_LF & CGCTATTAACTATTAACG & \\
\hline E1_LB & GCGCTTCGATTGTGTGCGT & \\
\hline
\end{tabular}

Ref: references where the DNA oligos where originally published or share the same set of primers. F3/B3: outer forward (F) and backward primers; FIP/BIP: inner primers; LF/LB: loop primers. For detailed information on targeted SARS-CoV-2 sequence used, please refer to Supplementary Figures S3-S5 and Figure 9. 


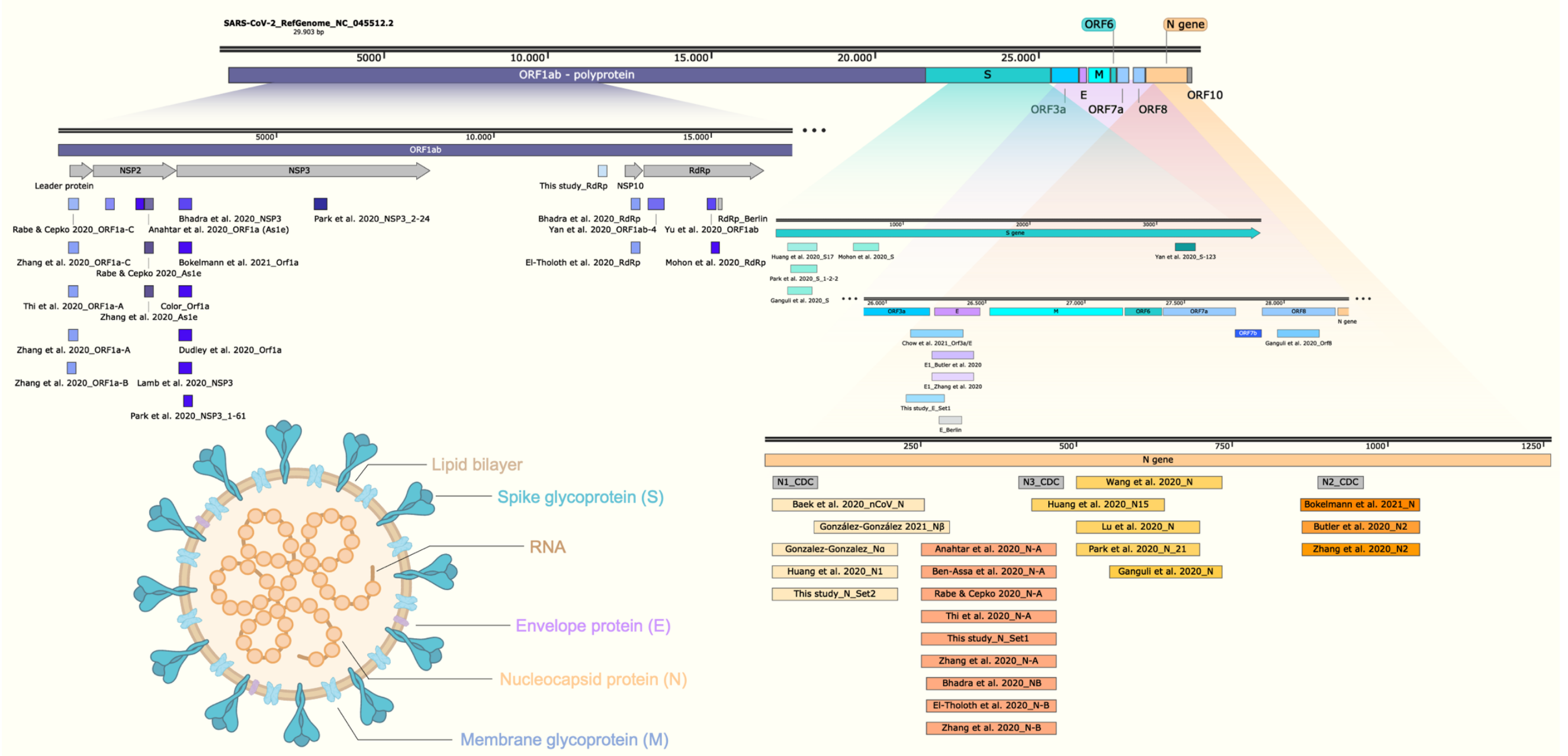

Figure 9 - Schematic representation of SARS-CoV-2 genome indicating the amplicons for the COVID-19 molecular diagnostics by RT-LAMP. Structural representation of SARS-CoV-2 virion shows the main particle parts. LAMP primer regions are indicated as previously reported $(9,12-$ 14,16,17,24,26,28,30,36-38,42,43,52,63,65,85,86); ORF: open reading frame; RdRp: RNA-dependent RNA polymerase; NSP: non-structural protein. Schematic representation created using Snap Gene Viewer software version 5.0.7; N1, N2 and N3_CDC correspond to the amplicons for SARS-CoV2 detection by RT-PCR (86). 
medRxiv preprint doi: https://doi.org/10.1101/2021.05.26.21257488; this version posted June 2, 2021. The copyright holder for this preprint (which was not certified by peer review) is the author/funder, who has granted medRxiv a license to display the preprint in perpetuity. It is made available under a CC-BY-NC-ND 4.0 International license .

\section{RT-LAMP assays}

All mix preparations for RT-LAMP reaction were performed on ice inside a biosafety level 2 cabinet. RT-LAMP reactions were performed according to New England Biolabs (NEB) recommendations, containing the following components: $10 \mu \mathrm{L}$ of WarmStart ${ }^{\circledR}$ Colorimetric LAMP 2x Master Mix (NEB \#M1800 or \#M1804, the latter contains dUTP UDG - uracil-DNAglycosylase - to avoid carryover contamination; composition of both are NEB's proprietary) ready to use mixture of WarmStart $^{\circledR}$ Bst 2.0 DNA polymerase and WarmStart ${ }^{\circledR}$ RTx (reverse transcriptase for one-step transcription/amplification reaction) in presence of a $\mathrm{pH}$ sensor that turns from fuchsia (pink) to yellow in presence of increased proton (acid $\mathrm{pH}$ ) during DNA polymerization on isothermal amplification; $1.6 \mu \mathrm{mol} / \mathrm{L}$ forward inner/backward inner primers (FIP/BIP); $0.2 \mu \mathrm{mol} / \mathrm{L}$ forward and backward outer primers (F3/B3) and $0.4 \mu \mathrm{mol} / \mathrm{L}$ loop forward and loop backward primers (LF/LB); Ultra-pure ${ }^{\mathrm{TM}}$ DNAse/RNase free distilled water (Invitrogen ${ }^{\mathrm{TM}} \# 10977015$ ) was added in quantity enough to complete the final volume reaction of $20 \mu \mathrm{L}$; isothermal amplification was performed on Veriti ${ }^{\mathrm{TM}}$ thermal cycler (Applied Biosystems, Foster City, CA. USA) at $65^{\circ} \mathrm{C}$ for 30 minutes. From clinical samples, we used as input, $1 \mu \mathrm{L}$ of RNA extracted from nasopharyngeal swab placed on guanidine-containing VTM. When using raw RNA extraction free samples, we initially prepared a 1:10 ultra-pure water diluted clinical sample ( $1 \mu \mathrm{L}$ of VTM sample in $9 \mu \mathrm{L}$ water) and used $1 \mu \mathrm{L}$ as RT-LAMP reaction input. A similar strategy was applied to SARS-CoV-2 VOC/VOI samples. Positive controls were performed either by RNA extraction from Vero E6-derived inactivated SARS-CoV-2, using synthetic SARS-CoV-2 N geneharboring plasmid (ECRA Biotech, Campinas, SP, Brasil \#EB14-20) or inactivated laboratorycultured SARS-CoV-2, when aiming the RNA extraction free tests. For optimization purposes, incubation time tested varied from 30 to $50 \mathrm{~min}$. All RT-LAMP reaction products were migrated in 2\% agarose gel to confirm: specific amplification in positive reactions and amplicon-free nontemplate controls. Gel images were taken using the ImageQuant ${ }^{\mathrm{TM}}$ LAS 4000 with GelRed $^{\circledR}$ (Biotium \#41003) as intercalating dye. Non SARS-CoV-2 RNA extracted samples of Influenza A, Influenza B, human respiratory syncytial virus, Dengue, Zika and Chikungunya viruses were also added as $1 \mu \mathrm{L}$ input.

\section{Analytical sensitivity}


medRxiv preprint doi: https://doi.org/10.1101/2021.05.26.21257488; this version posted June 2, 2021. The copyright holder for this preprint (which was not certified by peer review) is the author/funder, who has granted medRxiv a license to display the preprint in perpetuity. It is made available under a CC-BY-NC-ND 4.0 International license .

Absolute quantification was performed based on a calibration curve prepared using the standard SARS-CoV-2 E gene-harboring plasmid $\left(2 \times 10^{5}\right.$ copies $\left./ \mu \mathrm{L}\right)($ Biogene COVID-19 PCR, Bioclin/Quibasa \#K228-1; Lot: 0007); SARS-CoV-2 (2019-nCoV) Charité/Berlin primer probe panel (IDT, \#10006804) and the GoTaq ${ }^{\circledR}$ Probe 1-step RT-qPCR System (Promega \#A6120), according to manufacturer instructions, as indicated by the United States Centers for Disease Control and Prevention (CDC). Real-time reverse transcriptase-polymerase chain reaction program was performed as follows: $1^{\text {st }}$ stage (x1) 15 min at $45^{\circ} \mathrm{C} ; 2^{\text {nd }}$ stage (x1) 2 min at $95^{\circ} \mathrm{C}$ and $3^{\text {rd }}$ stage $(\mathrm{x} 40) 3 \mathrm{sec}$ at $95^{\circ} \mathrm{C}$ followed by $30 \mathrm{sec}$ at $55^{\circ} \mathrm{C}$. Linear regression was performed using Prism software, version 9 (GraphPad Software, San Diego, CA, USA) leading to the equation: $\boldsymbol{Y}=-3.6383 \mathrm{X}+38.771$ and coefficient of correlation $\boldsymbol{R}^{2}=0.9938$ (Supplementary Figure S2). Viral RNA either from Vero E6-derived SARS-CoV-2 (SARS-CoV-2 isolate HIAE-02: SARS-CoV2/SP02/human/2020/BRA GenBank accession number MT126808.1) or obtained from clinical nasopharyngeal swabs was quantitated based on the cycle-threshold value for E gene.

\section{ACKNOWLEDGMENTS}

We thank Professor Édison L. Durigon, Laboratório de Virologia Clínica e Molecular, ICB/USP, São Paulo, Brazil, who kindly provided inactivated samples of SARS-CoV-2 isolate HIAE-02: SARS-CoV2/SP02/human/2020/BRA (GenBank accession number MT126808.1). We thank Dr. Luciano Moreira, Instituto René Rachou - Fiocruz Minas, for providing the first colorimetric LAMP buffers during the testing and optimization phase. We also thank Dr. Marluce Aparecida Assunção Oliveira - Former Director of Instituto Octávio Magalhães, Fundação Ezequiel Dias, Laboratório Central de Saúde Pública de Minas Gerais - LACEN-MG; and Dr. Marcos Vinicius Ferreira da Silva, head of virology service at LACEN-MG, for providing samples of Influenza A and B viruses and human respiratory syncytial virus (hRSV). We are grateful to to Cristiane P. Gomes and Patrícia P. N. Miranda for resources management and excellent technical assistance. This work was funded by: Fundação de Amparo à Pesquisa do Estado de Minas Gerais - Fapemig, grant number \#APQ-00485-20, to RLMN; grant number \#APQ-00262-20 to F.D.C. and Fundação Oswaldo Cruz - Inova Fiocruz Program - Innovative Products (grant number VPPIS-004-FIO-18-51) to RLMN; Innovative Products to face COVID-19 pandemics (grant number VPPIS-005-FIO-20-2-45) to PAA and from the MCTI - Brazilian Ministry of Science, Technology and Innovation, through the "Rede Virus" initiative to P.A.A (grant number - FINEP 
medRxiv preprint doi: https://doi.org/10.1101/2021.05.26.21257488; this version posted June 2, 2021. The copyright holder for this preprint (which was not certified by peer review) is the author/funder, who has granted medRxiv a license to display the preprint in perpetuity. It is made available under a CC-BY-NC-ND 4.0 International license.

01.20.0005.00). E.G.O. received a Master's fellowship from the Vice presidency of Education, Formation and communication VPEIC - Fundação Oswaldo Cruz. IAB and APMFL received postdoctoral research fellowships from Inova Fiocruz Program - Fundação Oswaldo Cruz. ABG holds a science, technology and innovation development scholarship from Fapemig (BDCTI-I). LAT is a post-doctoral fellow from MCTI (CNPq - DTI-A). R.L.M.N., S.M.R.T., G.W. and G.L.W. are CNPq Research Fellows (\#310640/2017-2; \#302961/2017-8; \#303902/2019-1; \#307538/2019-2). P.M holds a scholarship from Coordenação de Aperfeiçoamento de Nível Superior (CAPES/Ação Emergencial). The funders had no role in the study design, data collection and analysis, decision to publish or manuscript preparation. P.A.A, G.L.W and R.L.M.N. are part of Fiocruz COVID-19 Genomic Surveillance Network

\section{Conflict of interest}

H.R.M is part of Visuri company. Results presented here are the basis of a COVID-19 RT-LAMP diagnostic test offered by Visuri named OmniLAMP ${ }^{\circledR}$ SARS-CoV-2 kit. P.A.A. and R.L.M.N. are scientific advisors at CEPHA Biotech. The other authors declare no financial or non-financial conflict of interests 
medRxiv preprint doi: https://doi.org/10.1101/2021.05.26.21257488; this version posted June 2, 2021. The copyright holder for this preprint

(which was not certified by peer review) is the author/funder, who has granted medRxiv a license to display the preprint in perpetuity.

It is made available under a CC-BY-NC-ND 4.0 International license .

\section{REFERENCES}

1. Wang C, Horby PW, Hayden FG, Gao GF. A novel coronavirus outbreak of global health concern. Lancet. 2020;470-3.

2. Zhu N, Zhang D, Wang W, Li X, Yang B, Song J, et al. A Novel Coronavirus from Patients with Pneumonia in China, 2019. New England Journal of Medicine. 2020 Feb 20;382(8):727-33.

3. Rambaut A, Holmes EC, O'Toole Á, Hill V, McCrone JT, Ruis C, et al. A dynamic nomenclature proposal for SARS-CoV-2 lineages to assist genomic epidemiology. Nature Microbiology. 2020 Nov;5(11):1403-7.

4. Gorbalenya AE, Baker SC, Baric RS, de Groot RJ, Drosten C, Gulyaeva AA, et al. The species Severe acute respiratory syndrome-related coronavirus : classifying 2019-nCoV and naming it SARS-CoV-2. Nature Microbiology. 2020 Apr;5(4):536-44.

5. Bai Y, Yao L, Wei T, Tian F, Jin D-Y, Chen L, et al. Presumed Asymptomatic Carrier Transmission of COVID-19. JAMA. 2020 Apr 14;323(14):1406-7.

6. Rothe C, Schunk M, Sothmann P, Bretzel G, Froeschl G, Wallrauch C, et al. Transmission of 2019-nCoV Infection from an Asymptomatic Contact in Germany. New England Journal of Medicine. 2020 Mar 5;382(10):970-1.

7. Long Q-X, Tang X-J, Shi Q-L, Li Q, Deng H-J, Yuan J, et al. Clinical and immunological assessment of asymptomatic SARS-CoV-2 infections. Nature Medicine. 2020 Jun 18;1-5.

8. Esbin MN, Whitney ON, Chong S, Maurer A, Darzacq X, Tjian R. Overcoming the bottleneck to widespread testing: a rapid review of nucleic acid testing approaches for COVID-19 detection. RNA. 2020;26(7):771-83.

9. Anahtar MN, McGrath GEG, Rabe BA, Tanner NA, White BA, Lennerz JKM, et al. Clinical Assessment and Validation of a Rapid and Sensitive SARS-CoV-2 Test Using Reverse Transcription Loop-Mediated Isothermal Amplification Without the Need for RNA Extraction. Open Forum Infectious Diseases [Internet]. 2021 Feb 1 [cited 2021 Apr 18];8(ofaa631). Available from: https://doi.org/10.1093/ofid/ofaa631

10. Godfrey K, Bagust L, Baird J, Barker M, Batchelor J, Bryant S, et al. Evaluation of the expanded Southampton pilot study (Phase 2) for use of saliva-based lamp testing in asymptomatic populations: Final report, 16th November 2020 [Internet]. University of Southampton; 2020 [cited 2021 May 13]. Available from: https://eprints.soton.ac.uk/445622/

11. Park G-S, Ku K, Baek S-H, Kim S-J, Kim SI, Kim B-T, et al. Development of Reverse Transcription Loop-Mediated Isothermal Amplification Assays Targeting Severe Acute Respiratory Syndrome Coronavirus 2 (SARS-CoV-2). The Journal of Molecular Diagnostics. 2020 Jun 1;22(6):729-35. 
medRxiv preprint doi: https://doi.org/10.1101/2021.05.26.21257488; this version posted June 2, 2021. The copyright holder for this preprint

(which was not certified by peer review) is the author/funder, who has granted medRxiv a license to display the preprint in perpetuity. It is made available under a CC-BY-NC-ND 4.0 International license .

12. Yan C, Cui J, Huang L, Du B, Chen L, Xue G, et al. Rapid and visual detection of 2019 novel coronavirus (SARS-CoV-2) by a reverse transcription loop-mediated isothermal amplification assay. Clinical Microbiology and Infection. 2020 Jun;26(6):773-9.

13. Yu L, Wu S, Hao X, Dong X, Mao L, Pelechano V, et al. Rapid Detection of COVID-19 Coronavirus Using a Reverse Transcriptional Loop-Mediated Isothermal Amplification (RTLAMP) Diagnostic Platform. Clin Chem [Internet]. [cited 2020 Jul 6]; Available from: https://academic.oup.com/clinchem/advancearticle/doi/10.1093/clinchem/hvaa102/5823294

14. Dudley DM, Newman CM, Weiler AM, Ramuta MD, Shortreed CG, Heffron AS, et al. Optimizing direct RT-LAMP to detect transmissible SARS-CoV-2 from primary nasopharyngeal swab samples. PLOS ONE. 2020 Dec 31;15(12):e0244882.

15. Wang D. One-pot Detection of COVID-19 with Real-time Reverse-transcription Loopmediated Isothermal Amplification (RT-LAMP) Assay and Visual RT-LAMP Assay. bioRxiv. 2020 Apr 22;2020.04.21.052530.

16. El-Tholoth M, Bau HH, Song J. A Single and Two-Stage, Closed-Tube, Molecular Test for the 2019 Novel Coronavirus (COVID-19) at Home, Clinic, and Points of Entry. 2020 Feb 19 [cited $2020 \mathrm{Jul}$ 8]; Available from: https://chemrxiv.org/articles/preprint/A_Single_and_Two-Stage_ClosedTube_Molecular_Test_for_the_2019_Novel_Coronavirus_COVID19_at_Home_Clinic_and_Points_of_Entry/11860137

17. Baek YH, Um J, Antigua KJC, Park J-H, Kim Y, Oh S, et al. Development of a reverse transcription-loop-mediated isothermal amplification as a rapid early-detection method for novel SARS-CoV-2. Emerging Microbes \& Infections. 2020 Jan 1;9(1):998-1007.

18. Li Y, Fan P, Zhou S, Zhang L. Loop-mediated isothermal amplification (LAMP): A novel rapid detection platform for pathogens. Microbial Pathogenesis. 2017 Jun 1;107:54-61.

19. Mori Y, Notomi T. Loop-mediated isothermal amplification (LAMP): a rapid, accurate, and cost-effective diagnostic method for infectious diseases. J Infect Chemother. 2009 Apr;15(2):62-9.

20. Kurosaki Y, Magassouba N, Oloniniyi OK, Cherif MS, Sakabe S, Takada A, et al. Development and Evaluation of Reverse Transcription-Loop-Mediated Isothermal Amplification (RTLAMP) Assay Coupled with a Portable Device for Rapid Diagnosis of Ebola Virus Disease in Guinea. PLoS Negl Trop Dis. 2016 Feb;10(2):e0004472.

21. Kurosaki Y, Magassouba N, Bah HA, Soropogui B, Doré A, Kourouma F, et al. Deployment of a Reverse Transcription Loop-Mediated Isothermal Amplification Test for Ebola Virus Surveillance in Remote Areas in Guinea. J Infect Dis. 2016 Oct 15;214(suppl 3):S229-33. 
medRxiv preprint doi: https://doi.org/10.1101/2021.05.26.21257488; this version posted June 2, 2021. The copyright holder for this preprint

(which was not certified by peer review) is the author/funder, who has granted medRxiv a license to display the preprint in perpetuity. It is made available under a CC-BY-NC-ND 4.0 International license .

22. Silva SJR da, Paiva MHS, Guedes DRD, Krokovsky L, Melo FL de, Silva MAL da, et al. Development and Validation of Reverse Transcription Loop-Mediated Isothermal Amplification (RT-LAMP) for Rapid Detection of ZIKV in Mosquito Samples from Brazil. Sci Rep. 2019 Mar 14;9(1):4494.

23. Gonçalves D da S, Cassimiro APA, de Oliveira CD, Rodrigues NB, Moreira LA. Wolbachia detection in insects through LAMP: loop mediated isothermal amplification. Parasit Vectors. 2014 May 19;7:228.

24. Zhang Y, Odiwuor N, Xiong J, Sun L, Nyaruaba R, Wei H, et al. Rapid Molecular Detection of SARS-CoV-2 (COVID-19) Virus RNA Using Colorimetric LAMP. 2020 Feb 29 [cited 2020 Jul 6]; Available from: https://europepmc.org/article/ppr/ppr115157

25. Tanner NA, Zhang Y, Evans TC. Visual detection of isothermal nucleic acid amplification using pH-sensitive dyes. Biotechniques. 2015 Feb;58(2):59-68.

26. Rabe BA, Cepko C. SARS-CoV-2 detection using isothermal amplification and a rapid, inexpensive protocol for sample inactivation and purification. PNAS. 2020 Sep 29;117(39):24450-8.

27. L'Helgouach N, Champigneux P, Santos-Schneider F, Molina L, Espeut J, Alali M, et al. EasyCOV : LAMP based rapid detection of SARS-CoV-2 in saliva. medRxiv. 2020 May 30;2020.05.30.20117291.

28. Chow FW-N, Chan TT-Y, Tam AR, Zhao S, Yao W, Fung J, et al. A Rapid, Simple, Inexpensive, and Mobile Colorimetric Assay COVID-19-LAMP for Mass On-Site Screening of COVID-19. International Journal of Molecular Sciences. 2020 Jan;21(15):5380.

29. Bektaş A, Covington MF, Aidelberg G, Arce A, Matute T, Núñez I, et al. Accessible LAMPEnabled Rapid Test (ALERT) for Detecting SARS-CoV-2. Viruses. 2021 May;13(5):742.

30. Bokelmann L, Nickel O, Maricic T, Pääbo S, Meyer M, Borte S, et al. Point-of-care bulk testing for SARS-CoV-2 by combining hybridization capture with improved colorimetric LAMP. Nature Communications. 2021 Mar 5;12(1):1467.

31. Broughton JP, Deng X, Yu G, Fasching CL, Servellita V, Singh J, et al. CRISPR-Cas12-based detection of SARS-CoV-2. Nature Biotechnology. 2020 Apr 16;1-5.

32. Joung J, Ladha A, Saito M, Segel M, Bruneau R, Huang MW, et al. Point-of-care testing for COVID-19 using SHERLOCK diagnostics [Internet]. Infectious Diseases (except HIV/AIDS); 2020 May [cited 2020 Aug 16]. Available from: http://medrxiv.org/lookup/doi/10.1101/2020.05.04.20091231

33. Faria NR, Claro, IM, Candido D, Franco LAM, Andrade PS, Coletti TM, et al. Genomic characterisation of an emergent SARS-CoV-2 lineage in Manaus: preliminary findings SARS-CoV-2 coronavirus / nCoV-2019 Genomic Epidemiology [Internet]. Virological. 2021 
medRxiv preprint doi: https://doi.org/10.1101/2021.05.26.21257488; this version posted June 2, 2021. The copyright holder for this preprint

(which was not certified by peer review) is the author/funder, who has granted medRxiv a license to display the preprint in perpetuity. It is made available under a CC-BY-NC-ND 4.0 International license .

[cited 2021 May 14]. Available from: https://virological.org/t/genomic-characterisation-ofan-emergent-sars-cov-2-lineage-in-manaus-preliminary-findings/586

34. Aoki MN, de Oliveira Coelho B, Góes LGB, Minoprio P, Durigon EL, Morello LG, et al. Colorimetric RT-LAMP SARS-CoV-2 diagnostic sensitivity relies on color interpretation and viral load. Scientific Reports. 2021 Apr 27;11(1):9026.

35. Asprino P, Bettoni F, Camargo A, Coelho D, Coppini G, Correa I, et al. A scalable salivabased, extraction-free rt-lamp protocol for sars-cov-2 diagnosis. medRxiv. 2020 Oct 27;2020.10.27.20220541.

36. Ben-Assa N, Naddaf R, Gefen T, Capucha T, Hajjo H, Mandelbaum N, et al. Direct on-thespot detection of SARS-CoV-2 in patients. Exp Biol Med (Maywood). 2020 Aug;245(14):1187-93.

37. Bhadra S, Riedel TE, Lakhotia S, Tran ND, Ellington AD. High-surety isothermal amplification and detection of SARS-CoV-2, including with crude enzymes. bioRxiv. $2020 \mathrm{Jul}$ 7;2020.04.13.039941.

38. Butler DJ, Mozsary C, Meydan C, Danko D, Foox J, Rosiene J, et al. Shotgun Transcriptome and Isothermal Profiling of SARS-CoV-2 Infection Reveals Unique Host Responses, Viral Diversification, and Drug Interactions. bioRxiv. 2020 May 1;2020.04.20.048066.

39. de Oliveira Coelho B, Sanchuki HBS, Zanette DL, Nardin JM, Morales HMP, Fornazari B, et al. Essential properties and pitfalls of colorimetric Reverse Transcription Loop-mediated Isothermal Amplification as a point-of-care test for SARS-CoV-2 diagnosis. Mol Med. 2021 Mar 26;27(1):30.

40. Flynn MJ, Snitser O, Flynn J, Green S, Yelin I, Szwarcwort-Cohen M, et al. A simple direct RTLAMP SARS-CoV-2 saliva diagnostic. medRxiv. 2020 Nov 22;2020.11.19.20234948.

41. Fowler VL, Armson B, Gonzales JL, Wise EL, Howson ELA, Vincent-Mistiaen Z, et al. A highly effective reverse-transcription loop-mediated isothermal amplification (RT-LAMP) assay for the rapid detection of SARS-CoV-2 infection. medRxiv. 2020 Oct 25;2020.06.30.20142935.

42. Ganguli A, Mostafa A, Berger J, Aydin MY, Sun F, Ramirez SAS de, et al. Rapid isothermal amplification and portable detection system for SARS-CoV-2. PNAS. 2020 Sep 15;117(37):22727-35.

43. González-González E, Lara-Mayorga IM, Rodríguez-Sánchez IP, Zhang YS, Martínez-Chapa SO, Santiago GT, et al. Colorimetric loop-mediated isothermal amplification (LAMP) for cost-effective and quantitative detection of SARS-CoV-2: the change in color in LAMPbased assays quantitatively correlates with viral copy number. Anal Methods. 2021 Jan 21;13(2):169-78. 
medRxiv preprint doi: https://doi.org/10.1101/2021.05.26.21257488; this version posted June 2, 2021. The copyright holder for this preprint

(which was not certified by peer review) is the author/funder, who has granted medRxiv a license to display the preprint in perpetuity. It is made available under a CC-BY-NC-ND 4.0 International license .

44. Huang WE, Lim B, Hsu C-C, Xiong D, Wu W, Yu Y, et al. RT-LAMP for rapid diagnosis of coronavirus SARS-CoV-2. Microbial Biotechnology. 2020;13(4):950-61.

45. Inaba M, Higashimoto $Y$, Toyama $Y$, Horiguchi T, Hibino $M$, Iwata $M$, et al. Diagnostic accuracy of LAMP versus PCR over the course of SARS-CoV-2 infection. International Journal of Infectious Diseases [Internet]. 2021 Apr 12 [cited 2021 May 1];0(0). Available from: https://www.ijidonline.com/article/S1201-9712(21)00329-5/abstract

46. Kitagawa Y, Orihara Y, Kawamura R, Imai K, Sakai J, Tarumoto N, et al. Evaluation of rapid diagnosis of novel coronavirus disease (COVID-19) using loop-mediated isothermal amplification. J Clin Virol. 2020 Aug;129:104446.

47. Lalli MA, Langmade JS, Chen X, Fronick CC, Sawyer CS, Burcea LC, et al. Rapid and Extraction-Free Detection of SARS-CoV-2 from Saliva by Colorimetric Reverse-Transcription Loop-Mediated Isothermal Amplification. Clin Chem. 2021 Jan 30;67(2):415-24.

48. Lu R, Wu X, Wan Z, Li Y, Jin X, Zhang C. A Novel Reverse Transcription Loop-Mediated Isothermal Amplification Method for Rapid Detection of SARS-CoV-2. Int J Mol Sci. 2020 Apr 18;21(8).

49. Nawattanapaiboon $K$, Pasomsub E, Prombun $P$, Wongbunmak A, Jenjitwanich $A$, Mahasupachai $P$, et al. Colorimetric reverse transcription loop-mediated isothermal amplification (RT-LAMP) as a visual diagnostic platform for the detection of the emerging coronavirus SARS-CoV-2. Analyst. 2021 Jan 21;146(2):471-7.

50. Österdahl MF, Lee KA, Lochlainn MN, Wilson S, Douthwaite S, Horsfall R, et al. Detecting SARS-CoV-2 at point of care: preliminary data comparing loop-mediated isothermal amplification (LAMP) to polymerase chain reaction (PCR). BMC Infectious Diseases. 2020 Oct 20;20(1):783.

51. Sherrill-Mix S, Duyne GDV, Bushman FD. Molecular beacons allow specific RT-LAMP detection of B.1.1.7 variant SARS-CoV-2. medRxiv. 2021 Mar 26;2021.03.25.21254356.

52. Thi VLD, Herbst K, Boerner K, Meurer M, Kremer LP, Kirrmaier D, et al. A colorimetric RTLAMP assay and LAMP-sequencing for detecting SARS-CoV-2 RNA in clinical samples. Science Translational Medicine [Internet]. 2020 Aug 12 [cited 2021 Apr 18];12(556). Available from: https://stm.sciencemag.org/content/12/556/eabc7075

53. Wei S, Kohl E, Djandji A, Morgan S, Whittier S, Mansukhani M, et al. Direct diagnostic testing of SARS-CoV-2 without the need for prior RNA extraction. Scientific Reports. 2021 Jan 28;11(1):2402.

54. Zhang Y, Ren G, Buss J, Barry AJ, Patton GC, Tanner NA. Enhancing colorimetric loopmediated isothermal amplification speed and sensitivity with guanidine chloride. BioTechniques. 2020 Jul 8;69(3):178-85. 
medRxiv preprint doi: https://doi.org/10.1101/2021.05.26.21257488; this version posted June 2, 2021. The copyright holder for this preprint

(which was not certified by peer review) is the author/funder, who has granted medRxiv a license to display the preprint in perpetuity. It is made available under a CC-BY-NC-ND 4.0 International license .

55. Rhoads D, Peaper DR, She RC, Nolte FS, Wojewoda CM, Anderson NW, et al. College of American Pathologists (CAP) Microbiology Committee Perspective: Caution must be used in interpreting the Cycle Threshold (Ct) value. Clinical Infectious Diseases: An Official Publication of the Infectious Diseases Society of America. 2020 Aug 12;

56. García-Bernalt Diego J, Fernández-Soto $P$, Domínguez-Gil M, Belhassen-García M, Bellido JLM, Muro A. A Simple, Affordable, Rapid, Stabilized, Colorimetric, Versatile RT-LAMP Assay to Detect SARS-CoV-2. Diagnostics. 2021 Mar;11(3):438.

57. Schermer B, Fabretti F, Damagnez M, Cristanziano VD, Heger E, Arjune S, et al. Rapid SARSCoV-2 testing in primary material based on a novel multiplex RT-LAMP assay. PLOS ONE. 2020 Nov 2;15(11):e0238612.

58. Kim M-C, Cui C, Shin K-R, Bae J-Y, Kweon O-J, Lee M-K, et al. Duration of Culturable SARSCoV-2 in Hospitalized Patients with Covid-19. New England Journal of Medicine. 2021 Feb 18;384(7):671-3.

59. Jang WS, Lim DH, Yoon J, Kim A, Lim M, Nam J, et al. Development of a multiplex LoopMediated Isothermal Amplification (LAMP) assay for on-site diagnosis of SARS CoV-2. PLOS ONE. 2021 Mar 3;16(3):e0248042.

60. Mautner L, Baillie C-K, Herold HM, Volkwein W, Guertler P, Eberle U, et al. Rapid point-ofcare detection of SARS-CoV-2 using reverse transcription loop-mediated isothermal amplification (RT-LAMP). Virology Journal. 2020 Oct 21;17(1):160.

61. Kim JH, Kang M, Park E, Chung DR, Kim J, Hwang ES. A Simple and Multiplex Loop-Mediated Isothermal Amplification (LAMP) Assay for Rapid Detection of SARS-CoV. BioChip J. 2019 Dec 1;13(4):341-51.

62. Wilson-Davies ESW, Mahanama AIK, Samaraweera B, Ahmed N, Friar S, Pelosi E. Concerning the OptiGene Direct LAMP assay, and it's use in at-risk groups and hospital staff. J Infect. $2021 \mathrm{Feb} ; 82(2): 282-327$.

63. Mohon AN, Oberding L, Hundt J, van Marle G, Pabbaraju K, Berenger BM, et al. Optimization and clinical validation of dual-target RT-LAMP for SARS-CoV-2. Journal of Virological Methods. 2020 Dec 1;286:113972.

64. Srivatsan S, Han PD, Raay K van, Wolf CR, McCulloch DJ, Kim AE, et al. Preliminary support for a "dry swab, extraction free" protocol for SARS-CoV-2 testing via RT-qPCR. bioRxiv. 2020 Apr 23;2020.04.22.056283.

65. Lamb LE, Bartolone SN, Ward E, Chancellor MB. Rapid detection of novel coronavirus/Severe Acute Respiratory Syndrome Coronavirus 2 (SARS-CoV-2) by reverse transcription-loop-mediated isothermal amplification. PLOS ONE. 2020 Jun 12;15(6):e0234682. 
medRxiv preprint doi: https://doi.org/10.1101/2021.05.26.21257488; this version posted June 2, 2021. The copyright holder for this preprint

(which was not certified by peer review) is the author/funder, who has granted medRxiv a license to display the preprint in perpetuity. It is made available under a CC-BY-NC-ND 4.0 International license .

66. Yang Q, Meyerson NR, Clark SK, Paige CL, Fattor WT, Gilchrist AR, et al. Saliva TwoStep for rapid detection of asymptomatic SARS-CoV-2 carriers. medRxiv. 2021 Feb 16;2020.07.16.20150250.

67. Newman CM, Ramuta MD, McLaughlin MT, Wiseman RW, Karl JA, Dudley DM, et al. Initial evaluation of a mobile SARS-CoV-2 RT-LAMP testing strategy. medRxiv. 2021 Feb 28;2020.07.28.20164038.

68. Smyrlaki I, Ekman M, Lentini A, Rufino de Sousa N, Papanicolaou N, Vondracek M, et al. Massive and rapid COVID-19 testing is feasible by extraction-free SARS-CoV-2 RT-PCR. Nature Communications. 2020 Sep 23;11(1):4812.

69. ECDC TAB. Rapid increase of a SARS-CoV-2 variant with multiple spike protein mutations observed in the United Kingdom. 2020 Dec 20;13.

70. Tegally H, Wilkinson E, Giovanetti M, Iranzadeh A, Fonseca V, Giandhari J, et al. Detection of a SARS-CoV-2 variant of concern in South Africa. Nature. 2021 Apr;592(7854):438-43.

71. Shah M, Ahmad B, Choi S, Woo HG. Mutations in the SARS-CoV-2 spike RBD are responsible for stronger ACE2 binding and poor anti-SARS-CoV mAbs cross-neutralization. Computational and Structural Biotechnology Journal. 2020 Jan 1;18:3402-14.

72. Li C, Tian X, Jia X, Wan J, Lu L, Jiang S, et al. The impact of receptor-binding domain natural mutations on antibody recognition of SARS-CoV-2. Signal Transduction and Targeted Therapy. 2021 Mar 23;6(1):1-3.

73. Davies NG, Jarvis Cl, Edmunds WJ, Jewell NP, Diaz-Ordaz K, Keogh RH. Increased mortality in community-tested cases of SARS-CoV-2 lineage B.1.1.7. Nature. 2021 May;593(7858):2704.

74. Davies NG, Abbott S, Barnard RC, Jarvis Cl, Kucharski AJ, Munday JD, et al. Estimated transmissibility and impact of SARS-CoV-2 lineage B.1.1.7 in England. Science [Internet]. 2021 Apr 9 [cited 2021 May 14];372(6538). Available from: https://science.sciencemag.org/content/372/6538/eabg3055

75. Voloch CM, Francisco R da S, Almeida LGP de, Cardoso CC, Brustolini OJ, Gerber AL, et al. Genomic Characterization of a Novel SARS-CoV-2 Lineage from Rio de Janeiro, Brazil. Journal of Virology [Internet]. 2021 Apr 26 [cited 2021 May 14];95(10). Available from: https://jvi.asm.org/content/95/10/e00119-21

76. Resende PC, Bezerra JF, Teixeira Vasconcelos RH, Arantes I, Appolinario L, Mendonça AC, et al. Severe Acute Respiratory Syndrome Coronavirus 2 P. 2 Lineage Associated with Reinfection Case, Brazil, June-October 2020. Emerg Infect Dis. 2021 Apr 22;27(7).

77. Resende PC, Gräf T, Paixão ACD, Appolinario L, Lopes RS, Mendonça AC da F, et al. A Potential SARS-CoV-2 Variant of Interest (VOI) Harboring Mutation E484K in the Spike 
medRxiv preprint doi: https://doi.org/10.1101/2021.05.26.21257488; this version posted June 2, 2021. The copyright holder for this preprint

(which was not certified by peer review) is the author/funder, who has granted medRxiv a license to display the preprint in perpetuity. It is made available under a CC-BY-NC-ND 4.0 International license .

Protein Was Identified within Lineage B.1.1.33 Circulating in Brazil. Viruses. $2021 \mathrm{Apr}$ $21 ; 13(5)$.

78. Resende PC, Delatorre E, Gräf T, Mir D, Motta FC, Appolinario LR, et al. Evolutionary Dynamics and Dissemination Pattern of the SARS-CoV-2 Lineage B.1.1.33 During the Early Pandemic Phase in Brazil. Front Microbiol. 2020;11:615280.

79. Resende PC, Gräf T, Lima Neto LGL, Silva FV da, Paixão ACD, Appolinario L, et al. Identification of a new B.1.1.33 SARS-CoV-2 Variant of Interest (VOI) circulating in Brazil with mutation E484K and multiple deletions in the amino (N)-terminal domain of the Spike protein - SARS-CoV-2 coronavirus / nCoV-2019 Genomic Epidemiology [Internet]. Virological. 2021 [cited 2021 May 14]. Available from: https://virological.org/t/identification-of-a-new-b-1-1-33-sars-cov-2-variant-of-interestvoi-circulating-in-brazil-with-mutation-e484k-and-multiple-deletions-in-the-amino-nterminal-domain-of-the-spike-protein/675

80. Brown KA, Gubbay J, Hopkins J, Patel S, Buchan SA, Daneman N, et al. S-Gene Target Failure as a Marker of Variant B.1.1.7 Among SARS-CoV-2 Isolates in the Greater Toronto Area, December 2020 to March 2021. JAMA [Internet]. 2021 Apr 8 [cited 2021 May 14]; Available from: https://jamanetwork.com/journals/jama/fullarticle/2778599

81. Sherrill-Mix S, Hwang Y, Roche AM, Glascock A, Weiss SR, Li Y, et al. LAMP-BEAC: Detection of SARS-CoV-2 RNA Using RT-LAMP and Molecular Beacons. medRxiv. $2021 \mathrm{Apr}$ $16 ; 2020.08 .13 .20173757$.

82. Bezerra MF, Machado LC, do Carmo Vasconcelos de Carvalho V, Docena C, Brandão-Filho SP, Ayres CFJ, et al. A Sanger-based approach for scaling up screening of SARS-CoV-2 variants of interest and concern. Infection, Genetics and Evolution. 2021 May 8;104910.

83. Parida M, Sannarangaiah S, Dash PK, Rao PVL, Morita K. Loop mediated isothermal amplification (LAMP): a new generation of innovative gene amplification technique; perspectives in clinical diagnosis of infectious diseases. Rev Med Virol. 2008 Dec;18(6):407-21.

84. Miranda P, Weber G. Thermodynamic evaluation of the impact of DNA mismatches in PCRtype SARS-CoV-2 primers and probes. Molecular and Cellular Probes. $2021 \mathrm{Apr}$ 1;56:101707.

85. Huang WE, Lim B, Hsu C-C, Xiong D, Wu W, Yu Y, et al. RT-LAMP for rapid diagnosis of coronavirus SARS-CoV-2. Microbial Biotechnology. 2020;13(4):950-61.

86. Lu X, Wang L, Sakthivel SK, Whitaker B, Murray J, Kamili S, et al. US CDC Real-Time Reverse Transcription PCR Panel for Detection of Severe Acute Respiratory Syndrome Coronavirus 2 - Volume 26, Number 8-August 2020 - Emerging Infectious Diseases journal - CDC. 
medRxiv preprint doi: https://doi.org/10.1101/2021.05.26.21257488; this version posted June 2, 2021. The copyright holder for this preprint (which was not certified by peer review) is the author/funder, who has granted medRxiv a license to display the preprint in perpetuity. It is made available under a CC-BY-NC-ND 4.0 International license.

[cited 2020 Oct 5]; Available from: https://wwwnc.cdc.gov/eid/article/26/8/201246_article 